IZA DP No. 9562

Girls' Schooling Choices and Home Production: Evidence from Pakistan

Hugo Reis

December 2015 


\title{
Girls' Schooling Choices and Home Production: Evidence from Pakistan
}

\author{
Hugo Reis \\ Bank of Portugal, \\ Católica Lisbon School of Business and Economics \\ and IZA
}

Discussion Paper No. 9562

December 2015

IZA

P.O. Box 7240

53072 Bonn

Germany

Phone: +49-228-3894-0

Fax: +49-228-3894-180

E-mail: iza@iza.org

\begin{abstract}
Any opinions expressed here are those of the author(s) and not those of IZA. Research published in this series may include views on policy, but the institute itself takes no institutional policy positions. The IZA research network is committed to the IZA Guiding Principles of Research Integrity.

The Institute for the Study of Labor (IZA) in Bonn is a local and virtual international research center and a place of communication between science, politics and business. IZA is an independent nonprofit organization supported by Deutsche Post Foundation. The center is associated with the University of Bonn and offers a stimulating research environment through its international network, workshops and conferences, data service, project support, research visits and doctoral program. IZA engages in (i) original and internationally competitive research in all fields of labor economics, (ii) development of policy concepts, and (iii) dissemination of research results and concepts to the interested public.
\end{abstract}

IZA Discussion Papers often represent preliminary work and are circulated to encourage discussion. Citation of such a paper should account for its provisional character. A revised version may be available directly from the author. 
IZA Discussion Paper No. 9562

December 2015

\section{ABSTRACT \\ Girls' Schooling Choices and Home Production: Evidence from Pakistan*}

The paper develops and estimates a dynamic structural model that allows for the interrelations between girls' schooling and mothers' labor market participation decision, in a rural area of Pakistan where drop-out rates are considerably high. The model incorporates home production, which is critical for understanding the behavior of mothers when deciding girls' schooling. Results suggest that monetary incentives are a good mechanism to increase girls' school enrollment, but not the most cost effective. The impact of the conditional cash transfer program on secondary school enrollment rate was only one third of the impact of the school building program. Regarding welfare, the difference between schemes is smaller. Results also highlight the effectiveness of the role of conditionality.

JEL Classification: $\quad 125,128$

Keywords: girls' schooling, home production, development economics, structural model, discrete choice dynamic programming models

Corresponding author:

Hugo Reis

Economic Research Department

Banco de Portugal

Av. Almirante Reis 71

1150-012 Lisboa

Portugal

E-mail: hfreis@bportugal.pt

\footnotetext{
* I am particularly thankful to Pedro Carneiro, Orazio Attanasio, and Mónica Costa Dias for discussions and insights. I also have benefited from insightful comments made by Petra Todd, Lars Nesheim, Michael Keane, Aureo de Paula, Pierre-André Chiappori, Jishnu Das, Pat Kehoe, Dan Black, Sankar Mukhopadhyay, participants at the $13^{\text {th }}$ IZA/SOLE Transatlantic Meeting of Labor Economists, and at the Northeast Universities Development Consortium (NEUDC) 2014 Conference. Hugo Reis acknowledges the support of Fundação para a Ciência e Tecnologia, World Bank, and Banco de Portugal.
} 


\section{Introduction}

It is widely acknowledged that human capital plays a critical role in economic growth of developing countries, which has enhanced the efforts toward educational participation, in particular among poor children and girls ${ }^{1}$. Lower income countries have made great strides in terms of school enrollment, with a net primary enrollment rate close to 90 percent and a net secondary enrollment rate above 60 percent in 2012 (on average over all countries). However, Pakistan is still far behind, reaching only 72 percent and 36 percent respectively (World Bank (2014)). Therefore, despite the efforts, educational participation in Pakistan is far from the targets proposed by several international institutions, like the United Nations, especially for girls ${ }^{2}$.

In most developing countries women's literacy rates are dramatically low. Women are clearly situated at the bottom or lower end of the educational system in comparison to their male counterparts, particularly in rural and sub-urban areas. Consequently, education can play a vital role in enhancing the status of women. An educated mother tends to have more influence in household decisions and her education may allow her to obtain more resources for her children, providing better education and health care ${ }^{3}$. Also, more educated mothers have fewer children and invest more in children, facilitating demographic transition. Moreover, an educated girl is more likely to be self-confident, to make more informed decisions, to participate more in the formal labor market, to earn more income, to marry later, and to have smaller families. This is critical given the strong role of women's education on human capital of future generations (e.g. Behrman et al. (1999)). Therefore, it is important to understand the reason for low levels of investment in girls' education in developing countries, independently of a suitable efficiency analysis ${ }^{4}$.

This paper develops and estimates a dynamic structural model in which mothers make labor and consumption decisions along with girls' schooling decisions. The model allows for the analysis of interrelations between girls' schooling choices and mothers' labor par-

\footnotetext{
${ }^{1}$ Policy makers have implemented several measures, namely conditional cash transfer (CCT) programs (Fiszbein and Schady (2009)) and gender-targeted CCT (e.g. Female School Stipend Program in Punjab, Pakistan) in order to explicitly address intra-household disparities in human capital investment.

${ }^{2}$ Concerning education, Pakistan is far behind the Millennium Development Goals (MDG) regarding Universal Primary Education. According to the MDG (2010) report, in 2012 the Pakistani net primary enrollment ratio and the literacy rate were below 60 percent overall (below 50 percent for girls in both cases).

${ }^{3}$ Mothers' education is highly related to their children's educational attainment. There is an extensive empirical literature on the strong association between parental schooling and children's outcomes focusing on developed and developing countries surveyed in Behrman (1997).

${ }^{4}$ For instance, there is no market failure if households know private returns, if they are not altruists, and if they are not credit constrained. In the opposite scenario, there is an efficiency argument to be in favor of more educational participation (higher school enrollment). Finally, disregarding efficiency, government may simply have different preferences from households.
} 
ticipation decision. In the model the mother makes a time allocation decision for herself and for each child age 6 to 15 in a way similar to the one proposed by Bernal (2008) and Todd and Wolpin $(2006)^{5}$, using detailed information on the school choice decisions in the rural Punjab province, the largest state in Pakistan, contained in the Learning and Educational Achievement in Punjab Schools (LEAPS) dataset. However, we depart from their approach as we allow for the mother's labor supply decision and allow girls to drop out of school to work at home, modelling explicitly a home production function ${ }^{6}$. For example, it can be expected that a girl whose mother participates in the labor market would be more valuable at home, doing housework.

Our paper starts by asking what the key determinants of girls' schooling choices are, and in particular, how the value of Pakistani girls' time if used in home production affects their educational participation. Incorporating home production is important for understanding the behavior of mothers when deciding girls' schooling. In rural areas girls' time allocated to school decreases dramatically after the age of 12 , and these girls leave school to work at home, and not to work for a salary. Moreover, on average, girls aged 12-13 spend around 4 hours per day working at home, while the older ones (aged 14-15) spend around 9 hours per day, which corresponds more or less to the amount of time allocated by their mothers. Without home production it is difficult to account for all these features. The model also addresses the lack of school infrastructures, and is able to answer how transportation costs affect girls' educational participation.

The schooling-labor decision model developed in this paper builds on several strands of literature including dynamic models of occupational choices as in Keane and Wolpin (1997), dynamic model of employment-child care decisions of women as in Bernal (2008), and, more closely related, Attanasio et al. (2012) and Todd and Wolpin (2006), in which a dynamic schooling behavioral model is used to evaluate the impact of monetary incentives provided to families to increase their children's school attendance. These models are attractive because structural parameters are useful tools for the evaluation of counterfactual policies (Aguirregabiria and Mira (2010), Keane et al. (2011), and Todd and Wolpin (2010)). We extend the literature to a lower-income developing country and use the model to simulate girls' school participation under different scenarios. We quantify the effect on school attendance of monetary incentives such as (conditional) cash transfers and employment/wage subsidies, and the increase in the number of communities where a secondary

\footnotetext{
${ }^{5}$ In Bernal (2008) the mother makes child care and labor market participation decisions. In Todd and Wolpin (2006) married couples are assumed to make sequential decisions over a finite horizon about the time allocation of all of their children age 6 through 15, including their school attendance and labor market participation, and about the timing and spacing of births. Parents' labor supply decisions are not included in their model.

${ }^{6}$ In contrast to Todd and Wolpin (2006), and despite being a potentially interesting feature, we are not considering a childbirth decision in the model.
} 
school is available. The paper also discusses the impact of each policy in terms of welfare.

The parameters of the model are estimated by simulated maximum likelihood and fit the actual data well. The model replicates the observed distribution of schooling choices for each particular child's age, i.e., the key decision analyzed in the paper. In particular, the model accounts for the significant increase in drop-out rates after age 12. Furthermore, the model simulates the results from the gender targeted CCT program developed in Punjab reasonably well. As stated before, the results highlight not only the important role played by home production, capturing in part what can be called a marriage premium effect, but also the importance of having a secondary school in the village.

Policy simulations suggest that monetary incentives, such as the CCT, are a good mechanism to keep and increase girls' school enrollment but not necessarily the most cost effective. In this case this mechanism may be less effective, as in rural areas many girls leave school to help in housework, instead of working for a salary. From a policy perspective, reducing transportation costs in secondary school through a school building program is a good alternative at a similar cost. The impact of the cost comparable CCT program on older girls' school enrollment rate is only 34 percent as large as the school building program. Results also highlight the effectiveness of the role of conditionality, as emphasized recently by Baird et al. (2011) and Attanasio et al. (2015). The impact of the unconditional cash transfer (UCT) program on older girls' school enrollment rate is at most 28 percent that of the CCT scheme. The effect of these measures on mothers' labor market participation turns out to be negligible. In terms of welfare, the difference between schemes becomes

much smaller. In particular, for the older girls, the utility gain of the school building program is equivalent to an increase in income of around 3 percent and the CCT (cost comparable scheme) effect is 83 percent as large as the school building program. The anti-poverty nature of the CCT scheme is a natural explanation for this result.

The paper is organized as follows. In Section 2 we describe the structure of the model and estimation method. Section 3 describes the LEAPS data on which we estimate the model and highlights the overall patterns in the data. Section 4 presents the estimates of the model and evaluates its ability to fit the data. Section 5 shows the results from several policy experiments and Section 6 concludes.

\section{Behavior Model and Estimation}

This section presents a structural model of mothers' sequential decisions about work and childrens' schooling. In each discrete time period $t$, the mother makes a time allocation 
decision for herself and for each girl age 6 to $15^{7}$. The mother decides whether to send a daughter to school or to let the girl remain at home (after age 12 this implies working at home). At age 16 children are assumed to become independent and make their own schooling and work decisions. In contrast to the mothers' labor supply decision, fathers' income is exogenous and the household cannot save or borrow. Educational expenditure on children is also subtracted from parental income to determine consumption. Specifically, we allow for two mother working options \{work, no work $\}$ and two child schooling choices \{enrolled, not enrolled\} with a total of four possible options in a mother's choice set. The choice set is expressed as: $J=\left\{h_{t}, s_{t}: h_{t}=\{0,1\}\right.$ and $\left.s_{t}=\{0,1\}\right\}$, where $h_{t}$ is an indicator for whether or not the mother works in the market, and $s_{t}$ is an indicator for whether or not the girl is going to school in period t.

\subsection{Utility Function}

The current-period utility function given choice of option $\left(h_{t}, s_{t}\right)$ is given by:

$$
U_{t}\left(h_{t}, s_{t} ; \Omega_{t}\right)=\frac{1}{\gamma} C_{t}^{\gamma}+\alpha_{1} s_{t}+\alpha_{2} h_{t}+\epsilon_{t}^{\left(h_{t}, s_{t}\right)}
$$

where $C_{t}$ is total consumption, $\alpha_{1}$ and $\alpha_{2}$ are respectively the utility/disutility from sending a child to school and from working, and $\epsilon_{t}^{\left(h_{t}, s_{t}\right)}$ is an alternative-specific preference shock. The utility function has the common CRRA form in consumption $(\gamma)$.

\subsubsection{Consumption}

Total consumption is a composite of goods and services purchased in the market, $c_{t}^{M}$, and goods and services produced in the home, $c_{t}^{H}$. In particular,

$$
C_{t}=\left[\theta c_{t}^{M \rho}+(1-\theta) c_{t}^{H \rho}\right]^{\frac{1}{\rho}}
$$

and the parameter $\rho$ controls the household's willingness to substitute between $c_{t}^{M}$ and $c_{t}^{H}$ (the larger is $\rho$, the greater is this willingness).

Consumption in the market, $c_{t}^{M}$, is given by the budget constraint

$$
c_{t}^{M}=y_{t}+w_{t} h_{t}-f_{t} s_{t}-\psi v_{t} s_{t}
$$

The direct costs of attending school $\left(f_{t}\right)$ are the costs of buying books as well as clothing

\footnotetext{
${ }^{7}$ Note that siblings from the same mother have the same wage shock. In addition, as a robustness check, we estimate the model only for the older girls and we obtain similar results.
} 
items such as shoes ${ }^{8}$. The model allows for transportion costs, a parameter to be estimated $(\psi)$ that captures the effect of a village without a secondary school. If there is no school in a village it can become very costly to send a girl to school and this may be an important mechanism to explain the high drop-out rates among older girls. $v_{t}$ is a categorical variable that takes value 1 if the village has no secondary school. $y_{t}$ represents father's income and $w_{t}$ the wage income earned by the mother if she decides to work.

The mother's wage affects the children's schooling decision in two opposite ways. On one hand, if $w_{t}$ increases or the mother accepts a job there is an income effect. On the other hand, if the mother accepts a job or a higher wage this may lead older girls to stay at home to home-produce.

In addition to the budget constraint, in the spirit of Greenwood et al. (1993), the mother has a home production function:

$$
c_{t}^{H}=\left(\delta_{0}+\delta_{1} n_{05, t}\right)\left[\left(1-h_{t}\right)+\left(\eta_{0} a g e_{1213, t}^{c}+\eta_{1} a g e_{1415, t}^{c}\right)\left(1-s_{t}\right)\right]
$$

The home production function yields consumption of the home goods and services $\left(c_{t}^{H}\right)$ as a function of the time spent in home work of both mother $\left(1-h_{t}\right)$ and children $\left(1-s_{t}\right)$, and household characteristics, including the number of children less than 5 years old $\left(n_{05, t}\right)$. This is another important mechanism that may lead girls to drop out; their value at home may be greater if there are very young children in the household. The number of young children enters as a joint production $\left(\delta_{0}+\delta_{1} n_{05, t}\right)$, implying that home goods are produced at the same time and younger children do not change productivity of other home goods. We assume that home production is only technology. In addition, working at home is an option only after age 12 and we allow the value of having older girls at home to vary with age $\left(\eta_{0}\right.$ and $\left.\eta_{1}\right)$. This captures the different effect of girls aged $12-13$ vs. $14-15^{9}$. These terms seek to capture the increasing number of hours working at home by age observed in the data ${ }^{10}$. $a g e_{1213, t}^{c}$ and $a g e_{1415, t}^{c}$ are dummy variables that take value 1 when children are 12-13 and 14-15 years old, respectively. This specification of the home production function implies that $c_{t}^{H}$ is more/less valuable when the family has very young children if $\delta_{1}$ is positive/negative ${ }^{11}$.

\footnotetext{
${ }^{8}$ If a child is going to private school it should also include the tuition fee. However, the results do not change if we add this cost to the model. In the sample, around 30 percent of the students go to private school but the private schools are relatively affordable (see Carneiro et al. (2015) for details).

${ }^{9}$ Different specifications were used, including a quadratic form for children's age. This specification of the home production was determined in part using model fit criteria.

${ }^{10}$ Mothers spend on average around 9 hours per day working at home. Girls aged 12-13 working at home spend on average 4 hours per day, while the older ones (aged 14-15) spend more or less the same amount of time as mothers.

${ }^{11}$ Despite being a potentially interesting feature, we are not considering fertility decisions in the model, which in our setup does not influence the main results.
} 


\subsubsection{Wage}

One key factor is the mother's wage and we do not observe wages for mothers who are not working. We thus specify a standard Mincer type wage equation, in which the wage of a woman is determined by her age $\left(a g e_{t}^{m}\right)$, education $\left(e d u c_{t}^{m}\right)$, and local labor market conditions $\left(z_{t v}\right)$ in her village $v$ according to

$$
\ln w_{t}^{m}=\varphi_{0}+\varphi_{1} a g e_{t}^{m}+\varphi_{2} e d u c_{t}^{m}+\varphi_{3} z_{t v}+\xi_{t}^{m}
$$

where $\varphi_{0}$ represents the log price of human capital, which we assume to be the same across villages, and $\xi_{t}^{m} \sim N\left(0, \sigma_{w}^{2}\right)$ represents a wage shock $^{12}$.

Following Attanasio et al. (2012), we estimate this wage equation separately from the rest of the model using a Heckman selection model. We then use predictions from this equation in place of actual wages and use $\widehat{\sigma}_{w}^{2}\left(\xi_{t}^{m} \sim N\left(0, \widehat{\sigma}_{w}^{2}\right)\right)$ to introduce the wage shock in the model.

\subsubsection{Heterogeneity}

Finally, we allow for observed and unobserved heterogeneity in mother's tastes for work $\left(\alpha_{2}\right)$

$$
\alpha_{2, k}=\alpha_{21} e d u c_{t}^{m}+\alpha_{2} a g e_{t}^{m}+\overline{\alpha_{2, k}}
$$

and in their tastes for children's schooling $\left(\alpha_{1}\right)$ :

$$
\alpha_{1, k}=\alpha_{11} e d u c_{t}^{m}+\alpha_{12} a g e_{t}^{m}+\alpha_{13} a g e_{t}^{c}+\alpha_{14}\left(a g e_{t}^{c}\right)^{2}+\overline{\alpha_{1, k}}
$$

where $\overline{\alpha_{1, k}}$ and $\overline{\alpha_{2, k}}$ represent the unobservable heterogeneity of the children and mother, respectively. We assume that there are two different types $(\mathrm{k}=$ low and high). Associated type proportions are expressed by $\Pi=\left\{\pi_{l}^{m}, \pi_{h}^{m}, \pi_{l}^{c}, \pi_{h}^{c}\right\}$, which are parameters to be estimated (Heckman and Singer (1984)).

Finally, we allow the term $\epsilon_{t}^{\left(h_{t}, s_{t}\right)}$ to be correlated across alternatives, capturing the fact that some alternatives are more similar than others ${ }^{13}$. We assume to have a joint normal distribution and are serially uncorrelated.

\footnotetext{
${ }^{12}$ In the model siblings have the same wage shock.

${ }^{13}$ It is expected that the alternative of going to school and mother working is correlated with going to school and mother not working but completely unrelated with not going to school and mother not working.
} 


\subsection{Value Function}

At every period the agent chooses his action $(h, s) \in J$ to maximize expected utility at $t$, the value function, which is given by

$$
V_{t}\left(\Omega_{t}\right)=\max _{(h, s)_{t, \ldots T}} E\left\{\sum_{\tau=t}^{T} \beta^{\tau-t} U\left(h_{\tau}, s_{\tau} ; \Omega_{\tau}\right)+\beta^{T+1-t} V_{T+1}\left(\Omega_{T+1}\right) \mid \Omega_{t}\right\}
$$

where $\Omega_{t}=\left\{f_{t}, v_{t}, y_{t}, e d u c_{t}^{m}, e d u c_{t}^{c}, a g e_{t}^{m}, a g e_{t}^{c}, n_{05, t}, z_{t}, \epsilon_{t}, \xi_{t}^{w}, \pi\right\}$ represents the state space (all the relevant factors affecting current or future utility) at time $t$. The parameter $\beta$ represents the discount factor ${ }^{14}$.

The household maximizes the expected utility subject to

Budget Constraint

$$
c_{t}^{M}+f_{t} s_{t}+\psi v_{t} s_{t}=y_{t}+w_{t} h_{t}
$$

Home production equation

$$
c_{t}^{H}=h\left(\left(1-h_{t}\right),\left(1-s_{t}\right), n_{05, t}, a g e_{t}^{c}\right)
$$

Mother's Time Constraint

$$
h_{t} \in\{0,1\}
$$

Child's Time Constraint

$$
s_{t} \in\{0,1\}
$$

Mother's wage equation:

$$
\ln w_{t}^{m}=\varphi_{0}+\varphi_{1} a g e_{t}^{m}+\varphi_{2} e d u c_{t}^{m}+\varphi_{3} z_{t v}+\xi_{t}^{m}
$$

Children may not be successful in completing the grade, introducing an important source of uncertainty to the model.

Child Education law of motion:

$$
\begin{aligned}
e d u c_{t+1}^{c} & =e d u c_{t}^{c}+1 \text { if } s_{t} \neq 0 \text { and progress } \\
& =e d u c_{t}^{c} \quad \text { if } s_{t}=0 \text { or fail }
\end{aligned}
$$

In a dynamic programming framework, the value function can be written as the maximum over the alternative-specific value function, $V_{t}\left(h_{t}, s_{t} ; \Omega_{t}\right)$,

\footnotetext{
${ }^{14}$ Since we do not model savings and borrowing, this will reflect liquidity constraints or other factors that lead the households to disregard more or less the future.
} 


$$
V_{t}\left(\Omega_{t}\right)=\max _{\substack{h_{t} \in\{0,1\} \\ s_{t} \in\{0,1\}}}\left[V_{t}\left(h_{t}, s_{t} ; \Omega_{t}\right)\right]
$$

The choice-specific value function can be written as the expected discounted value that satisfies the Bellman equation:

$$
V_{t}\left(h_{t}, s_{t} ; \Omega_{t}\right)=U_{t}\left(h_{t}, s_{t} ; \Omega_{t}\right)+\beta E\left[\max _{\substack{h_{t+1} \in\{0,1\} \\ s_{t+1} \in\{0,1\}}} V_{t+1}\left(h_{t+1}, s_{t+1} ; \Omega_{t+1}\right) \mid \Omega_{t}, h_{t}, s_{t}\right]
$$

If a grade is not completed successfully, we assume that the level of education does not increase. This may be important since failure may discourage school attendance. We assume that the probability of failing to complete a grade is exogenous and does not depend on the willingness to continue schooling. However, we allow this probability to vary with the grade in question, with the age of the individual, and with the mother's education. Moreover, we assume that it is known to the individual ${ }^{15}$. In this case the choice-specific value function becomes:

$$
\begin{aligned}
V_{t}\left(h_{t}, s_{t} ; \Omega_{t}\right)=U_{t}\left(h_{t}, s_{t} ; \Omega_{t}\right)+ & \beta E\left\{p V_{t+1}\left(h_{t+1}, s_{t+1} ; e d u c_{t+1}^{c}=e d u c_{t}^{c}+1, \widetilde{\Omega_{t+1}}\right)\right. \\
& \left.+(1-p) V_{t+1}\left(h_{t+1}, s_{t+1} ; e d u c_{t+1}^{c}=e d u c_{t}^{c}, \widetilde{\Omega_{t+1}}\right)\right\}
\end{aligned}
$$

where

$$
\begin{aligned}
p & =\operatorname{Pr}\left(e d u c_{t+1}^{c}=e d u c_{t}^{c}+1 \mid s_{t} \neq 0 \text { and progress }\right) \\
\widetilde{\Omega} & =\Omega \backslash\left\{e d u c^{c}\right\}
\end{aligned}
$$

At $t=11$ (girls aged 16) the children's schooling decision is taken by the daughter and not by the mother. We assume a terminal value function that is a function of girls' level of education, using a linear approximation proposed by Eckstein and Lifshitz (2011):

$$
V_{T+1}\left(e d u c_{T+1}^{c}\right)=\phi e d u c_{T+1}^{c}
$$

This parameter is capturing mainly beliefs about returns to education and altruism. Using different specifications as in Bernal (2008), Attanasio et al. (2012), or Del Boca and Flinn (2014) does not seem to affect the main results ${ }^{16}$.

\footnotetext{
${ }^{15}$ We estimate the probability of progressing for each grade as the ratio of individuals who passed to the next grade compared to the year before at a particular age and mother's education (see Table A-3 in appendix).

${ }^{16}$ Bernal (2008)): $V_{T+1}\left(e d u c_{T+1}^{c}\right)=U_{T+1}\left(h_{t}, s_{t}, \Omega_{t}\right)+f\left(e d u c_{T+1}^{c}\right)$,

Attanasio et al. (2012): $V_{T+1}\left(e d u c_{T+1}^{c}\right)=\frac{\delta_{1}}{1+\exp \left(-\delta_{2} e d u c_{T+1}^{c}\right)}$, and
} 


\subsection{Likelihood}

Having solved the dynamic optimization problem, we are able to get the likelihood function. The probability that a mother chooses alternative $(h, s)=j$ at time $\mathrm{t}$ from her choice set $\mathrm{J}$ is given by:

$$
\operatorname{Pr}\left(\left(h_{t}, s_{t}\right)=j \mid \Omega_{t}\right)=\operatorname{Pr}\left[V_{t}^{j}\left(\Omega_{t}\right) \geq V_{t}^{q}\left(\Omega_{t}\right), \forall_{q \neq j \in J}\right]
$$

An individual contribution to the likelihood is:

$$
L_{i t}=\sum_{\pi \in \Pi}\left\{\prod_{t=t_{i}}^{T} \prod_{j \in J} \operatorname{Pr}\left(\left(h_{t}, s_{t}\right)=j \mid \Omega_{t}\right)^{1\left[\left(h_{t}, s_{t}\right)=j\right]}\right\} \pi
$$

where $t_{i}$ is the first observation available in the data for each individual $i$.

\subsubsection{Initial Condition}

We assume that the initial conditions are exogenous conditional on type except for the children's level of education $\left(e d u c_{t}^{c}\right)$. The presence of stock of education generates an important initial-conditions problem because we do not observe the entire history of schooling for the children in the sample, with the exception of those who are 6 years old.We cannot assume that the random variable in equation (7) is independent of past schooling decisions as reflected in the current level of schooling $\left(e d u c_{t}^{c}\right)$. To solve this problem we simulate life from 6 years of age until first available observation to obtain the education level simulated for each individual and each type ${ }^{17}$. Then, conditional on each type and age, we obtain the probability of each girl with a certain education level $\left(f\left(e d u c_{t}^{c} \mid \pi_{i}\right)\right.$, i.e., we construct the distribution of initial condition $\left(\widehat{f}\left(e d u c_{t}^{c} \mid \pi_{i}\right)^{18}\right.$.

Del Boca and Flinn (2014): $V_{T+1}\left(e d u c_{T+1}^{c}\right)=\delta e d u c_{T+1}^{c}(1-\beta)^{-1}$

${ }^{17} \mathrm{~A}$ girl who is 7 years old has 0 years of education (if not enrolled or failed) or 1 year of education (if pass). At 8 years old, a girl can have 0,1 , or 2 years of education. The same logic is applied for the subsequent ages.

${ }^{18}$ For example, $e d u c_{5}^{c}$ (first observation available) implying that $e d u c_{1}^{c}, e d u c_{2}^{c}, e d u c_{3}^{c}$, and $e d u c_{4}^{c}$ are not observed. With many draws we simulate life from 1 to 5 obtaining $e d u c_{5}^{c}$ simulated for each type and obtain $f\left(e d u c_{5}^{c} \mid \pi\right)$. 
Then we incorporate this correction in the likelihood ${ }^{19}$ :

$$
L_{i t}=\sum_{\pi \in \Pi}\left\{\prod_{t=t_{i}}^{T} \prod_{j \in J} \operatorname{Pr}\left(\left(h_{t}, s_{t}\right)=j \mid \Omega_{t}\right)^{1\left[\left(h_{t}, s_{t}\right)=j\right]} f\left(e d u c_{t}^{c} \mid \pi\right)\right\} \pi
$$

where $t_{i}$ is the first observation available in the data for each individual $i$.

Evaluation of the likelihood itself requires the calculation of three-variate integrals. We use a GHK recursive probability simulator (Keane (1994)) of the choice probabilities and form a simulated maximum likelihood estimator ${ }^{20}$.

\subsection{Identification Issues}

The influential works of Rust (1994) and Magnac and Thesmar (2002) have obtained negative results on the nonparametric identification of dynamic discrete structural models ${ }^{21}$. Therefore, it is unfortunately not possible to provide a rigorous proof of nonparametric identification for the parameters of the model ${ }^{22}$. Nevertheless, we provide some intuitive arguments regarding how the variation in the data aids in the parameters' identification. The identification comes also from the functional form assumed in the model.

We start the identification discussion on the home production parameters, as being one of the main focuses of the paper. In this case, for each period, the covariance between

$$
\begin{aligned}
& { }^{19} \text { Let } t=t_{i}, T \\
& \operatorname{Pr}\left(\left(h_{t}, s_{t}\right)=j \mid \Omega_{t}\right)^{1\left[\left(h_{t}, s_{t}\right)=j\right]} f\left(e d u c_{t}^{c} \mid e d u c_{t-1, \ldots,}^{c} e d u c_{t_{i}}^{c}, \pi\right) f\left(e d u c_{t-1}^{c} \mid e d u c_{t-2, \ldots,}^{c} e d u c_{t_{i}}^{c}, \pi\right) \ldots f\left(e d u c_{t_{i}}^{c} \mid \pi\right)
\end{aligned}
$$

In this case, $f\left(e d u c_{t}^{c} \mid e d u c_{t-1, \ldots,}^{c} e d u c_{t_{i}}^{c}, \pi\right)$ and $f\left(e d u c_{t-1}^{c} \mid e d u c_{t-2, \ldots,}^{c} e d u c_{t_{i}}^{c}, \pi\right)$ are deterministic and equal to 1 . Then, the correction to the contribution to the likelihood becomes only the term $f\left(e d u c_{t_{i}}^{c} \mid \pi\right)$. This term is simulated as discussed above.

${ }^{20}$ Geweke et al. (1994) present a detailed discussion and in a Monte Carlo study of alternative approaches to simulation based inference concluded that classic methods based on GHK outperformed classic methods based on kernel smoothed probability simulators. Train (2009) also provides a good discussion of GHK probability simulator.

The GHK probability simulator was calculated conditional on the wage shock $\left(\xi_{t}^{m}\right)$.

$$
\widehat{P_{j}}=\frac{1}{D} \sum_{d=1}^{D} \widehat{P_{G H K}}\left(\left(h_{t}, s_{t}\right)=j \mid \xi_{t}^{m}\right)
$$

\footnotetext{
${ }^{21}$ Magnac and Thesmar (2002) characterize the degree of non-identification and show that the model is identified subject to ad hoc assumptions on distributions of unobservables and functional forms of agents' preferences. Their identification result indicates that parametric specifications on the distributions of unobservables are indispensable for identifying the deep structural parameters of interest, which consequently motivates the maximum likelihood estimation. More recently, only under very specific conditions, Aguirregabiria (2010) provides a nonparametric approach to evaluating the behavioral and welfare effects of counterfactual policies using a dynamic structural model.

${ }^{22} \mathrm{We}$ have no problems in terms of convergence and the results are robust to different starting points. This is a necessary condition but naturally far from being a sufficient one.
} 
mothers' working choices and girls' schooling decision $\left(\operatorname{Cov}\left(h_{t}, s_{t}\right)\right)$ conditional on the number of young children $\left(n_{05, t}\right)$, children aged 12 and $13\left(a g e_{1213, t}^{c}\right)$, children aged 14 and 15 $\left(\right.$ age $\left.e_{1415, t}^{c}\right)$, helps in the identification of $\delta_{0}, \delta_{1}, \eta_{0}$, and $\eta_{1}$, the parameters of equation (4). In addition, the covariance between wages and mothers' working choices $\left(\operatorname{Cov}\left(w_{t}, h_{t}\right)\right)$ and between wages and girls' schooling decision $\left(\operatorname{Cov}\left(w_{t}, s_{t}\right)\right)$ are also an important source of variation that aid the identification of home production parameters.

Another important specification of the model is the heterogeneity in preferences, which characterizes mainly the cultural factors. Regarding preferences toward mothers' working decision, the covariance between mothers' working decision and mothers' education $\left(\operatorname{Cov}\left(h_{t}, e d u c_{t}^{m}\right)\right.$ and the covariance between mothers' decision and mothers' age $\left(\operatorname{Cov}\left(h_{t}, a g e_{t}^{m}\right)\right.$ are important sources to provide identification of $\alpha_{21}$ and $\alpha_{22}$ in equation (6), respectively. Concerning preferences toward girls' schooling decision, the parameters in equation (7), we can apply a similar argument. The covariance between girls' schooling decision and mothers' education $\left(\operatorname{Cov}\left(s_{t}, e d u c_{t}^{m}\right)\right)$ and the covariance between girls' schooling decision and mothers' age $\left(\operatorname{Cov}\left(s_{t}, a g e_{t}^{m}\right)\right)$ helps in the identification of $\alpha_{11}$ and $\alpha_{12}$, respectively. Furthermore, the relationship between girls' schooling decision and girls' age helps in the identification of $\alpha_{13}$ and $\alpha_{14}$; in particular we can think of the covariance between girls' schooling decision and girls' age $\left(\operatorname{Cov}\left(s_{t}, a g e_{t}^{c}\right)\right)$ and girls' age squared $\left(\operatorname{Cov}\left(s_{t},\left(a g e_{t}^{c}\right)^{2}\right)\right)$. Another important source of variation in the data comes from the father's income $\left(y_{t}\right)$, as the income effect becomes more important in this case. Thus, moments like the covariance between the father's income and mothers' working decision $\left(\operatorname{Cov}\left(y_{t}, h_{t}\right)\right)$ and the covariance of father's income and girls' schooling decision $\left(\operatorname{Cov}\left(y_{t}, s_{t}\right)\right)$ help in the identification of the preferences parameters. In addition, for the preferences toward girls' schooling decision an additional source of variation comes from the direct costs of attending school $\left(f_{t}\right)$.

The parameters regarding unobservable heterogeneity of the children and mother $\left(\overline{\alpha_{1, k}}\right.$ and $\overline{\alpha_{2, k}}$ ) and the type distribution $\Pi=\left\{\pi_{l}^{m}, \pi_{h}^{m}, \pi_{l}^{c}, \pi_{h}^{c}\right\}$ are also identified by each period choices. Heckman and Singer (1984) discuss the identification of unobserved heterogeneity related to duration models ${ }^{23}$.

The variation in the variable not having a school in the village $\left(v_{t}\right)$ conditional on other variables provides an important source of identification of the parameter capturing the cost of not having a school in the village $\psi$. The covariance between not having a school in the village and girls' schooling decision $\left(\operatorname{Cov}\left(v_{t}, s_{t}\right)\right)$ helps in the identification of this parameter.

Furthermore, moments relating mothers' working choices $\left(h_{t}\right)$ with girls' final education

\footnotetext{
${ }^{23}$ The idea is to allow for agents to differ in permanent ways unobserved to the econometrician and estimate the distribution of types to fit the persistence of various choices and outcomes of the agents. Naturally, if the number of types were allowed to approach the number of observations and allowed to vary over time, then the data could be fit perfectly.
} 
at age $16\left(e d u c_{T+1}^{c}\right)$ help the identification of the terminal value function parameter $(\phi)$.

In this framework, since the household cannot save or borrow, it works as we observe consumption. Therefore, consumption variation and moments relating choices with consumption help in the identification of the remaining parameters of the utility function.

Finally, we need to take the utility differences and to normalize for scale and level of utility to provide identification of the covariance matrix parameters. We take the difference against the alternative girls in school and mother not working choice and normalize the difference $\epsilon_{t}^{(1,1)}-\epsilon_{t}^{(0,1)}$ to 1 . Train (2009) discusses the identification of the variancecovariance matrix using the GHK simulation with maximum likelihood.

\section{Data}

The paper uses the Learning and Education Achievement in Punjab School (LEAPS) project data set ${ }^{24}$. The LEAPS data are collected from 112 villages in the Punjab province, the largest state in Pakistan, located in the three districts of Attock (North), Faisalabad (Center), and Rahim Yar Khan (South). Villages were chosen randomly from a list of those with at least one private school according to the 2000 census of private schools. This allows for the study of the differences between private and public schools in the same village. The baseline survey in 2004 covered 823 schools (government and private) and around 1800 households (with almost 6000 children, 48 percent of which are girls). Table A-1 in appendix presents the girls' age distribution between 6 and 15, which represents around 75 percent of all girls less than 15 years old.

Table 1 presents mean characteristics of the variables used in the model estimation. The mean age of the girls in the sample is 10.5 years with a level of education only slightly above 2 years. On average, the school enrollment rate is below 75 percent (around 80 percent between 6 and 11 years old and about 55 percent from 12 to 15) and only around 11 percent of the mothers work in the labor market. In addition, the mothers' mean age is 38 years (around 40 percent are more than 40 years old) and 75 percent of the mothers have no education. Households have on average one young child (less than 5 years old), and around 30 percent of the households have more than one. Regarding school availability, only around 60 percent of the sample have a secondary school in the village ${ }^{25}$. Father's income is, on average, about 7110 rupees (approximately 83 U.S. dollars). Among those mothers who worked, the average wage was about 1200 rupees (around 14 U.S. dollars) ${ }^{26}$.

\footnotetext{
${ }^{24}$ The project details are available at www.leapsproject.org.

${ }^{25}$ For only secondary schools the availability drops to around 40 percent.

${ }^{26} 1$ U.S. dollar $\approx 85.6$ Pakistani rupees
} 
Table 1: Sample summary statistics

\begin{tabular}{|c|c|c|c|c|c|}
\hline & Obs & Mean & Std.Dev & Min & Max \\
\hline Girls' school attendance ${ }^{d}$ & 1969 & 0.72 & 0.45 & 0 & 1 \\
\hline Mother's working status ${ }^{d}$ & 1969 & 0.11 & 0.32 & 0 & 1 \\
\hline Girls' age & 1969 & 10.5 & 2.73 & 6 & 15 \\
\hline Girls' education & 1969 & 2.28 & 2.23 & 0 & 8 \\
\hline Mother's education $^{d}$ - (with at least some education) & 1969 & 0.25 & 0.43 & 0 & 1 \\
\hline Mother's age ${ }^{d}-($ more than 40 years old $)$ & 1969 & 0.40 & 0.49 & 0 & 1 \\
\hline Mothers with at least one young child ${ }^{d}$ & 1969 & 0.62 & 0.49 & 0 & 1 \\
\hline Mothers with more than one young child ${ }^{d}$ & 1969 & 0.29 & 0.46 & 0 & 1 \\
\hline Girls in villages with secondary school ${ }^{d}$ & 1969 & 0.62 & 0.49 & 0 & 1 \\
\hline \multicolumn{6}{|l|}{ Female Local Labor Market Conditions } \\
\hline Good (low village unemployment rate) ${ }^{d}$ & 1969 & 0.36 & 0.48 & 0 & 1 \\
\hline Medium (medium village unemployment rate) ${ }^{d}$ & 1969 & 0.28 & 0.45 & 0 & 1 \\
\hline Bad (high village unemployment rate) ${ }^{d}$ & 1969 & 0.35 & 0.48 & 0 & 1 \\
\hline Father's income & 1969 & 7.11 & 8.51 & 0.34 & 209.73 \\
\hline
\end{tabular}

Notes: d - Categorical variables were used in order to obtain a more reasonable state space size. Budget constraint variables are expressed in rupees divided by 1000 . For example, the monthly average parents' income is equal to 7110 rupees $(\approx 83$ U.S. dollars).

Female Local Labor Market conditions is measured as the village female unemployment rate. Using the household census data we split the 125 villages into 3 categories according to their female unemployment rate (up to 25 th percentile, 25 th to 75 th percentile, and above 75 th percentile). The 25th percentile corresponds to an unemployment rate just below 6 percent and the 75 th percentile just above 30 percent.

Figure 1: Girls' school enrollment rate and mother working status

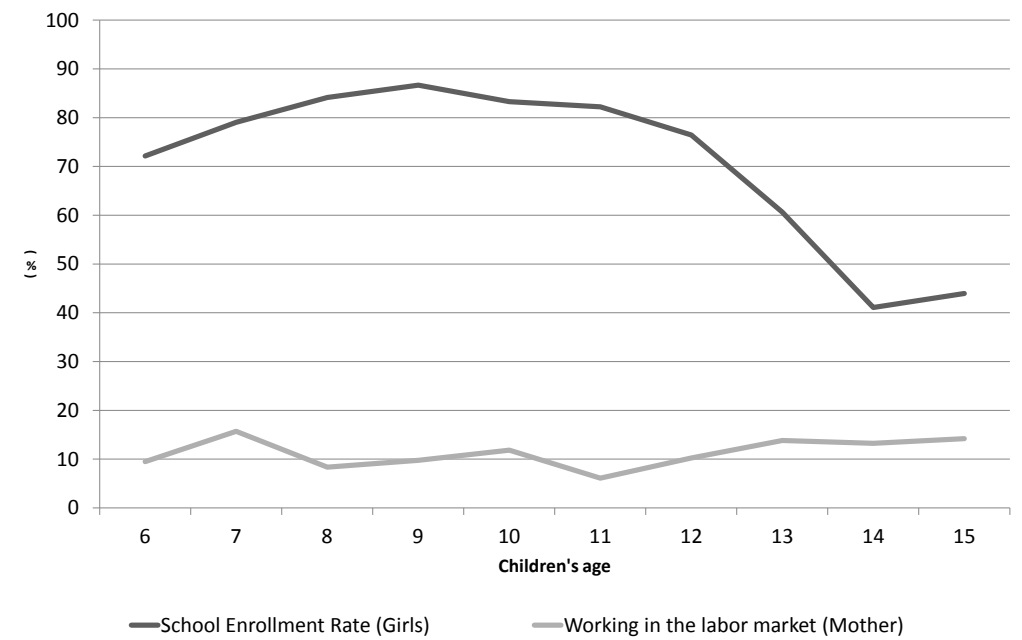

Note: This figure shows the girls' school enrollment rate and the percentage of mothers working in the labor market for girls between 6 and 15 years old. 
Figure 1 shows mother employment and child schooling choices of women in the sample with children between 6 and 15 years old. Enrollment rates decrease dramatically after 12 years old, reaching levels around 40 percent for the girls aged 14-15. In general, mother's labor market participation is low, without a clear girls' age pattern.

Figure A-1 in appendix shows the four mutually exclusive choices used in the model. Until 12 years old, around 75 percent of the mothers stayed at home and sent their girls to school, while for 15 percent both mother and children stay at home. Furthermore, 7 percent work and send their girls to school, and the remaining 3 percent work but the girls stay at home. When girls grow (between 13 and 15) it changes completely, the percentage of girls not in school with mother working in the market increased to around 8 percent, and in the case in which mother stays at home increased, as well, to around 40 percent.

\section{Results}

This section presents estimates of the structural model presented in Section 2. The estimation procedure involves a maximization of the likelihood function given by equation (13). We first solve the dynamic programming problem for each individual conditional on a given type and then write the probability function. As usual, we consider the reasonableness of the parameter values and the within sample fit. The use of some discrete variables, as described in Section 3, allowed us to obtain a size of state space that does not make the problem computationally intractable ${ }^{27}$.

\subsection{Estimation}

Table 2 reports the estimates of the parameters in the utility function, budget constraint, home production constraint, and observed heterogeneity. The second panel presents the unobservable heterogeneity parameters. Finally, the variance-covariance matrix is reported in Table A-2 in the appendix. The wage equation parameters used in the estimation of the model are reported in Table 3. The probability of a girl passing a grade at age $t$ with a mother's education $\left(e d u c^{m}\right)$ used in the estimation are reported in Table A-3 in the appendix.

Overall the estimated parameters, especially the most important from the policy perspective, have the expected signs and are statistically significant ${ }^{28}$. The discount factor was estimated to be 0.91 and it was obtained from a grid search over several values.

\footnotetext{
${ }^{27}$ We discretize the continuous state variables and solve for the Emax functions only on the grid of discretized values, i.e., we interpolate between grid points (see Keane et al. (2011)).

${ }^{28}$ The estimated CRRA parameter is similar to the result presented in Ahmed et al. (2012) of 0.58 and lies within the ranges of 0.05 and 2.57 for developing countries in Cardenas and Carpenter (2008).
} 
Table 2: Structural Parameters Estimates

\begin{tabular}{|c|c|c|}
\hline Parameter & Estimate & Std. Error \\
\hline \multicolumn{3}{|l|}{ Utility Function } \\
\hline \multicolumn{3}{|l|}{ Consumption } \\
\hline $\operatorname{CRRA}(\gamma)$ & 0.70 & 0.0001 \\
\hline Proportion of market and home production $(\theta)$ & 0.63 & 0.0009 \\
\hline Willingness to substitute between $c_{t}^{M}$ and $c_{t}^{H}(\rho)$ & 0.95 & 0.0001 \\
\hline \multicolumn{3}{|l|}{ Budget constraint } \\
\hline Transportion cost - Secondary School Not Available in the village $(\psi)$ & 2.29 & 0.0016 \\
\hline \multicolumn{3}{|l|}{ Home Production } \\
\hline Other goods/technological factor $\left(\delta_{0}\right)$ & 4.81 & 0.0006 \\
\hline Children from 0 to 5 years old $\left(\delta_{1}\right)$ & 4.31 & 0.0003 \\
\hline child contribution - 12 and 13 years old $\left(\eta_{0}\right)$ & 0.32 & 0.0001 \\
\hline child contribution - 14 and 15 years old $\left(\eta_{1}\right)$ & 2.90 & 0.0001 \\
\hline \multicolumn{3}{|l|}{ Observed heterogeneity in taste for child education } \\
\hline Mother's education $\left(\alpha_{11}\right)$ & 2.47 & 0.0009 \\
\hline Mother's Age $\left(\alpha_{12}\right)$ & -1.08 & 0.0007 \\
\hline Children's age $\left(\alpha_{13}\right)$ & 1.04 & 0.0002 \\
\hline Children's age squared $\left(\alpha_{14}\right)$ & -0.12 & 0.0002 \\
\hline \multicolumn{3}{|l|}{ Observed heterogeneity in taste for work } \\
\hline Mother's education on taste for work $\left(\alpha_{31}\right)$ & -0.37 & 0.0001 \\
\hline Mother's Age on taste for work $\left(\alpha_{32}\right)$ & 0.21 & 0.0009 \\
\hline Terminal value function - child education in $\mathrm{T}+1(\phi)$ & 1.96 & 0.0003 \\
\hline \multicolumn{3}{|l|}{ Unobservable heterogeneity } \\
\hline \multicolumn{3}{|l|}{ Children (taste for child education) } \\
\hline$\alpha_{1 l}($ type I - low $)$ & -3.15 & 0.0001 \\
\hline$\alpha_{1 h}$ (type II - high) & 3.98 & 0.0007 \\
\hline \multicolumn{3}{|l|}{ Type proportions } \\
\hline$\pi_{l}^{c}-$ type I & 0.35 & 0.0023 \\
\hline$\pi_{h}^{c}$-type II & 0.65 & - \\
\hline \multicolumn{3}{|l|}{ Mother (taste for work) } \\
\hline$\alpha_{3 l}($ type I - low $)$ & -2.41 & 0.0001 \\
\hline$\alpha_{3 h}($ type II - high) & 0.54 & 0.0006 \\
\hline \multicolumn{3}{|l|}{ Type proportions } \\
\hline$\pi_{l}^{m}-$ type I & 0.54 & 0.0026 \\
\hline$\pi_{h}^{m}$ - type II & 0.46 & \\
\hline Log likelihood & 5709.9 & \\
\hline
\end{tabular}

Notes: This table shows the estimated structural parameters and asymptotic standard errors. 
The results indicate significant heterogeneity among mother's types regarding both work and child education. Women are very different in their tastes for children's education. Although one of the types derives utility from sending children to school $\left(\alpha_{1, h}=4.0\right)$, the other type derives disutility from doing so $\left(\alpha_{1, l}=-3.2\right)$. Younger and more educated mothers have a clear preference for education in contrast to what happens with older and less educated ones. Mother's education seems to have a greater effect than age (2.5 and 1.1 , respectively).

Interestingly, utility is concave regarding children's age, explaining to some extent the hump-shaped form of the enrollment rate for girls (Figure A-2 in appendix). The utility from sending a girl to school increases up the age of $9 / 10$ years and decreases dramatically thereafter. The results suggest that parents derive very low utility if girls are 13 years old and disutility from sending girls to school when they reach 14 or 15 years old. Interestingly, 6 year old girls seem to be considered still too young to go to school, as the utility that parents derive from sending them to school is as low as the one derived from sending a 13 year old girl. These results can be explained to some extent with cultural factors and constraints, such as seclusion toward girls, that limit parents' willingness to send their girls to school. In addition, the most traditional attitudes toward girls' schooling tend to be held by the least educated, which derive less utility from educating girls as seen before, leading to a perpetuation of girls' disadvantage. Nevertheless, the main results are driven by the economic factors, as shown in sub-section 4.3 - robustness check.

Concerning tastes for work, one of the types obtains very low utility from work while the other has an outright dislike for it. Mother's education increases the disutility derived from work while age has the opposite effect. Nevertheless, both have a very modest impact on utility.

Among other economic factors, the results suggest that home production and especially the presence of young children in the household are important in explaining the high dropout rates among girls aged $12-15$ as $\delta_{1}$ is positive ${ }^{29}$. If this is the case, it is a rational efficient response to the economic environment.

The child's contribution to home production implies a significant difference between girls aged 12-13 and older girls. The coefficient associated with the younger ones is around 0.3 , while for those aged 14-15 it is significantly higher (2.9). These results should be compared to the mothers' term which is normalized to 1, the case where girls spend the same time working at home as mothers, or are as productive as mothers ${ }^{30}$. Data suggest

\footnotetext{
${ }^{29}$ Another implication of this finding is that if the number of younger children increases, we have less market consumption. Despite not being intuitive, this result becomes reasonable given that $c_{t}^{H}$ and $c_{t}^{M}$ are high substitutes $(\rho=0.95)$.

${ }^{30}$ These coefficients being higher/lower than 1 can only be explained by two reasons: spending more/less time than mothers at home and/or being more/less productive than mothers.
} 
that girls aged 14 to 15 spend around the same time at home as mothers. Therefore, the high value estimated by the model can be partly explained if girls are more productive than mothers. One possible explanation for the magnitude may be related to the incentives regarding marriage market premium. If this is the case, home production may also be capturing the fact that girls are being trained for marriage ${ }^{31}$. In addition, this parameter may be capturing the effect of other household members that are not taken directly into account in the model. Results for girls aged 12-13 are in line with the lower amount of time spent at home observed in the data.

Finally, the estimated cost of going to school if there is no secondary school available in the village is very high (around 2290 rupees $\approx 27$ U.S. dollars), which is around six times the average educational expenditure for those in grade 5 or above and around 30 percent of household income. Given the high percentage of villages without secondary schools (more than 40 percent), this result suggests that this might be an important factor explaining the high drop-out rate among older girls. From a policy perspective this is something that cannot be ignored by the authorities.

As discussed in Section 2, we estimate the wage equation outside the model and then use predictions from that equation in place of actual wages. We use a Heckman selection model to estimate the wage equation and test if selection is an issue or not. To obtain the Inverse Mills ratio to be used in the wage equation, we estimate a reduced form probit for labor market participation as a function of variables used in the structural model. These variables are mothers' age and education, number of children less than 1 year old, girls' school attendance, secondary school availability, and female unemployment rate in the village. The resulting estimated wage equation is presented in Table 3.

The selection effect is not an issue as the Inverse Mills ratio coefficient is not significant, reflecting to some extent the fact that female labor is relatively homogenous given age and education $^{32}$. Table 3 also shows that the education effect is significant and has the expected sign, while the age effect has the expected sign but is not significant. Local labor market conditions (female unemployment rate in the village) also seems to have some significant impact on wages. Nevertheless, the key determinant of wages at the individual level is education.

Note that in this type of model, to have identification we need at least one independent variable that affects selection but not the outcome. In our case we have number of children less than 6 years old, father's income, if child is in school, and secondary school availability

\footnotetext{
${ }^{31}$ In the data there is some evidence that boys are not leaving the house so early, which may suggest that some girls may be leaving home to get married.

${ }^{32}$ The Inverse Mills ratio has an unexpected sign, implying that those who go to the labor market tend to have lower wages. This result may be due to a strong income effect. Those who do not get a job are from a wealthier family.
} 
in the village ${ }^{33}$. All appear with the correct sign and are significant except the availability of secondary schools in the village. Therefore, a women with young children, with higher father income, and with children at school are less likely to work in the market.

Table 3: Wage equation

\begin{tabular}{lcc}
\hline Parameter & Estimate & Std.Error \\
\hline & & \\
Log wages equation & & \\
\hline Mother education & 0.79 & 0.21 \\
Mother age & -0.09 & 0.12 \\
Mother age squared / 100 & & 0.14 \\
Female Local Labor Market Conditions & -0.63 & 0.21 \\
Medium (medium village unemployment rate) & -0.39 & 0.20 \\
Bad (high village unemployment rate) & -0.14 & 0.21 \\
Inverse Mills ratio ( $\lambda$ ) & -1.13 & 2.50 \\
Constant & & \\
& & \\
First Step (Labor market participation) & 0.07 & 0.12 \\
\hline Mother education & 0.01 & 0.07 \\
Mother age & 0.01 & 0.08 \\
Mother age squared /100 & & \\
Female Local Labor Market Conditions & 0.19 & 0.12 \\
Medium (medium village unemployment rate) & 0.03 & 0.11 \\
Bad (high village unemployment rate) & -0.24 & 0.12 \\
Children from 0 to 5 years old & -0.18 & 0.10 \\
Children in school & -0.53 & 0.07 \\
Log income (father) & 0.05 & 0.11 \\
Secondary school availability in the village & -1.22 & 1.34 \\
Constant & & \\
\hline
\end{tabular}

Notes: This table shows the results of the wage equation estimated outside the model. The first block shows log wages equation (second step) while the second block displays mother's labor market participation decision. Female Local Labor Market conditions is measured as the village female unemployment rate. Using the household census data, we split the 125 villages into three categories according to their female unemployment rate (up to 25 th percentile, 25 th to 75 th percentile, and above 75 th percentile). The 25 th percentile corresponds to an unemployment rate just below 6 percent and the 75 th percentile just above 30 percent.

\subsection{Model Fit}

Figure 2 depicts the fit of the model to the choice distributions, based on a simulation of 10000 individuals. It compares the model's prediction of the distribution of children

\footnotetext{
${ }^{33}$ The availability of secondary schools in the village increases the likelihood of a woman participating in the labor market. This means that more secondary schools would increase the girls' enrollment and then more mothers would need to stay at home. Nevertheless, this result is not statistically significant.
} 
(school, or home) and mother (work, or home) activity allocations at individual ages with the actual distribution.

Figure 2: Model Fit - Girls' school enrollment and mother's working status

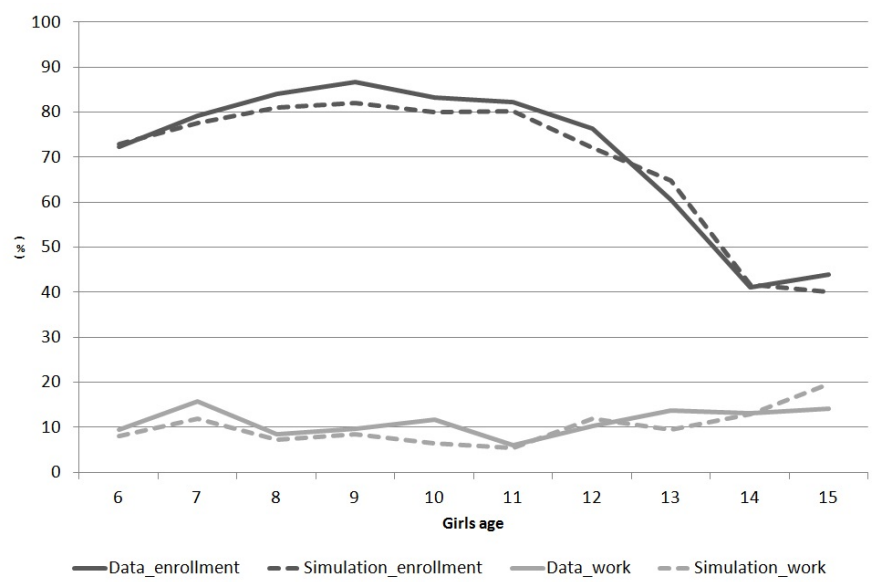

Notes: This figure shows the fit of the model to the mother's labor market participation (Data work vs. Simulation work) and girls' schooling (Data enrollment vs. Simulation enrollment), based on a simulation of 10000 individuals. It provides the fit of the model at each girls' age between 6 and 15 years old.

As can be seen, the model matches the data quite well, especially looking at the girl school enrollment decision. Despite not being the main focus of the paper, the mother's working status presents a reasonable result but a lower fit with data ${ }^{34}$. Figure A-3 in appendix shows that the within-sample fit of our model is particularly good in the case of the most chosen alternative, i.e., mother staying at home with children enrolled in school. The other alternatives present a reasonable match, with the exception of the first half of the distribution of the alternative of mother working and children staying at home. Furthermore, concerning girl school enrollment decision, the model also matches the data well if we look at households with and without young children (see Figure A-4 in appendix).

Table 4 presents the fit of the one-period transition rates by different group of ages for girls' schooling decisions. Once girls leave school, they rarely return. Only 5.5 percent of girls aged 11 to 15 who were at home (not enrolled) one year attended school the next year. The school-to-school transition also exhibits substantial persistence, with more than 90 percent of the girls aged 6 to 13 and around 83 percent of the girls aged 14 to 15 who attended school in one year also attending the following year.

As seen in Table 4, the model seems to capture the age group differences but it is not capturing schooling transition patterns very well, in particular, the not enrolled-to-enrolled transition rates. One concern is that lagged schooling status does not have an effect on

\footnotetext{
${ }^{34}$ In some situations the chi-square statistic associated with a test of the null that the predicted and actual distributions are the same is rejected.
} 
Table 4: One-period transition rates by age

\begin{tabular}{|c|c|c|c|c|c|}
\hline \multicolumn{4}{|c|}{ DATA } & \multicolumn{2}{|c|}{ MODEL } \\
\hline \multicolumn{4}{|c|}{$6-10$} & \multicolumn{2}{|c|}{$6-10$} \\
\hline & Not Enrolled (t) & Enrolled (t) & & Not Enrolled (t) & Enrolled (t) \\
\hline Not Enrolled (t-1) & 77.7 & 22.3 & Not Enrolled (t-1) & 47.1 & 52.9 \\
\hline Enrolled (t-1) & 5.4 & 94.6 & Enrolled (t-1) & 13.2 & 86.8 \\
\hline \multicolumn{3}{|c|}{$11-13$} & & \multicolumn{2}{|c|}{$11-13$} \\
\hline & Not Enrolled (t) & Enrolled (t) & & Not Enrolled (t) & Enrolled (t) \\
\hline Not Enrolled (t-1) & 94.3 & 5.7 & Not Enrolled (t-1) & 63.2 & 36.8 \\
\hline Enrolled (t-1) & 9.0 & 91.1 & Enrolled (t-1) & 19.3 & 80.7 \\
\hline \multicolumn{3}{|c|}{$14-15$} & & \multicolumn{2}{|c|}{$14-15$} \\
\hline & Not Enrolled (t) & Enrolled (t) & & Not Enrolled (t) & Enrolled (t) \\
\hline Not Enrolled (t-1) & 94.8 & 5.2 & Not Enrolled (t-1) & 72.7 & 27.3 \\
\hline Enrolled (t-1) & 17.4 & 82.6 & Enrolled (t-1) & 31.7 & 68.3 \\
\hline
\end{tabular}

Notes: This table shows the fit of the one-period transition rates (in percentage) by different group of ages for girls' schooling decisions.

current enrollment. In future research, a natural extension to the current model that deals with this problem is to include a cost of returning to school after dropping-out (a cost to re-entry to school). An additional source of dynamics is to make completion rate dependent on girls' effort and school quality simultaneously. This is important as the model does not incorporate dynamics to a great extent as utility depends mainly on school attendance and not on cognitive achievement.

\subsection{Robustness Check}

In this section we present two robustness checks on our previous results. We first consider a different model specification including father's income as endogenous to infer the reasonability in terms of identification of the conditional cash transfer experiment. We then check what happens to our results if we do not allow taste for school to vary with children's age.

Endogenous father's income - In this setup we re-estimate the model considering father's income as endogenous, depending on wife's age and education, male local labor market conditions, and an income shock. 
Father's income wage equation:

$$
y_{t}=g\left(a g e_{t}^{m}, e d u c_{t}^{m}, z_{t v}^{m a l e}, \varsigma_{t}^{y}\right)
$$

The estimation results are similar but the fit is not as good as in the exogenous case (Figure 3$)^{35}$. Nevertheless, the similarity with the exogenous case gives some assurance about the identification and interpretation of the cash transfer policy of our simulation.

Figure 3: Girls' school enrollment rate - Endogenous father's income case

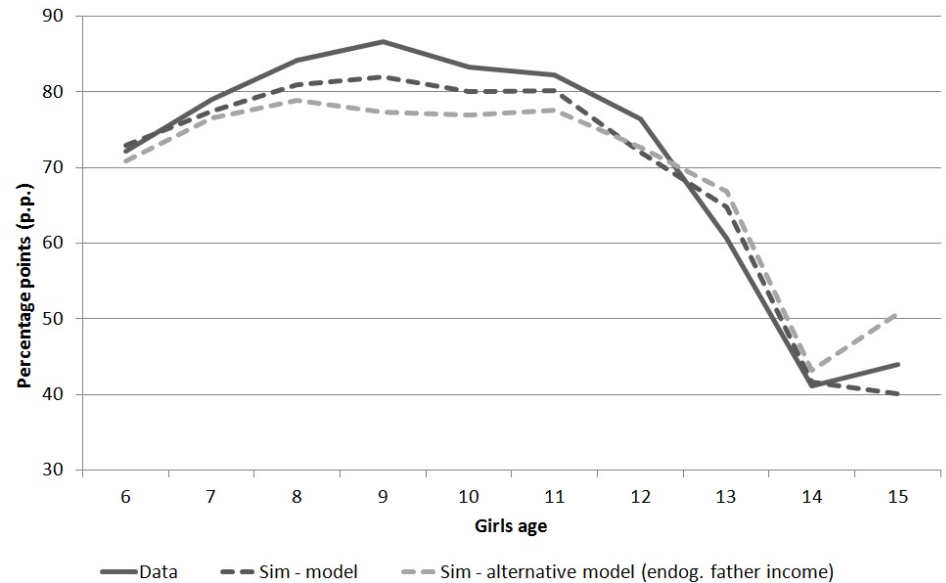

Notes: This figure compares the actual girls' school enrollment with the simulation of the model with and without father's income as endogenous. Alternative Model (endog. father income): The simulation of the alternative model implies the estimation of a new model with a different specification, including the father's alternative model implies the estimation of a new model with a different specification, including the fath
income $\left(y_{t}\right)$ as endogenous. It depends on mother's age, mother's education, male local labor market conditions, and income shock.

Children's age in the utility function - To check if economic factors are driving the results, in particular the dramatic decrease of enrollment rate for older girls, we perform two exercises: 1) simulate the model imposing the coefficients of children's age equal to zero $\left(\alpha_{13}=0\right.$ and $\left.\alpha_{14}=0\right)$, and 2 ) re-estimate the model with a new specification excluding children's age from the utility. Figure 4 shows that in both cases age naturally has some relevance but the main conclusions are still coming from the economic factors discussed before, especially for older girls. These exercises, simulation, and re-estimation of the model without children's age in the utility function, confirm that economic factors are the main determinants of the girls' enrollment rate. The result is particularly strong for older girls, but even the initial increase for younger girls is to some extent determined by economic factors and not entirely by the inclusion of age in a quadratic form in the utility function.

\footnotetext{
${ }^{35}$ The results are available upon request.
} 
Figure 4: Girls' school enrollment rate - Children's age case

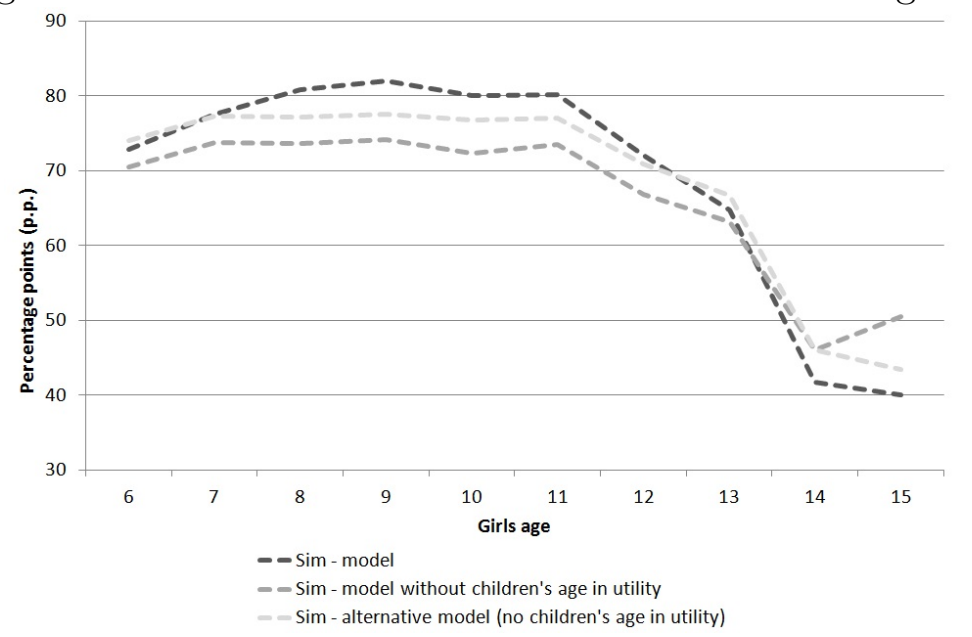

Notes: This figure compares the model simulation of the girls' school enrollment rate with two different model specifications: 1) Model without children's age in utility function: we simulate the model presented in the paper with the coefficients of age and age squared equal to zero $\left(\alpha_{13}=0\right.$ and $\left.\left.\alpha_{14}=0\right) ; 2\right)$ The simulation of the alternative model implies the estimation of a new model with a different specification excluding the terms $\alpha_{13}$ and $\alpha_{14}$ from the estimation.

\section{$5 \quad$ Policy Experiments}

One of the main advantages of having a structural model is the possibility of performing policy experiments. We now use the model to simulate school participation under different scenarios. We quantify the effect of demand-side policies such as (conditional) cash transfers, and employment/wage subsidy. We also present results of the effect of a supplyside policy on school attendance, i.e., the increase in the number of communities where a secondary school is available. We also discuss the impact of each policy on welfare.

In order to obtain credible results we need exogenous variation in the data related with the policy experiment. Therefore, we provide some intuitive arguments regarding the identification issues related to the effects of the policy experiments performed in this paper, i.e., policy relevant variation. The policy effect is estimated without direct policy variation, i.e., we did not need to observe households in both states of the world, for example, with and without the cash transfer program (Todd and Wolpin (2010)).

In the employment subsidy (wage variation) case, having policy relevant exogenous variation requires the presence of one variable in the wage equation that does not directly affect the utility of sending a girl to school. For example, female local labor market conditions enter the wage equation but do not directly affect preferences. Therefore, we assume that variation in the female local labor market factors might cause exogenous variation in employment and schooling decisions while not directly affecting preferences. For this argument to be valid we require the following assumptions: these local labor market conditions cannot vary across villages due to supply changes, for example, a common shock to women (e.g., to tastes to work) cannot affect local female unemployment rate, and there 
is no systematic variation in women's unobserved heterogeneity across villages.

In the case of the cash transfer policy, the argument is similar but applied to father's income instead of mother's wage ${ }^{36}$. As before, in this case male local labor market conditions in the father's income equation provide us with the required exogenous policy-relevant variation.

Finally, in the school building program, we assume that, conditional on other variables, variation in the variable not having a school in the village might plausibly generate exogenous variation in girls' schooling decisions. In that case, this assumption is enough to provide policy-relevant exogenous variation.

\subsection{Conditional Cash Transfer}

Conditional Cash Transfer (CCT) programs targeting poor households are rapidly becoming a key policy instrument used by developing countries to reduce poverty and increase human capital investments. To explicitly address intra-household disparities in human capital investment, some countries, including Pakistan, have implemented gender-targeted CCT.

We perform four alternative simulations with a gender CCT program: i) first we perform an exercise similar to the one implemented in Pakistan - Female School Stipend Program in Punjab; ii) then our approach follows closely the grant scheme implemented in Mexico (Oportunidades) with different grants for primary and secondary school ${ }^{37}$; iii) a scheme with the same grant for primary and secondary school, and iv) a grant scheme that would close the enrollment rate gender gap.

\subsubsection{Grant Scheme similar to the Female School Stipend Program in Punjab}

Under the Female School Stipend Program in Punjab eligible girls receive a stipend (of around 3 U.S dollars per month) conditional on her being enrolled in grade 6-8 in a government girls school in a target district and conditional on her maintaining average class attendance of at least 80 percent.

This program was evaluated by Chaudhury and Parajuli (2010) ${ }^{38}$ and Hasan (2010) with an impact on school enrollment rate between 2 and 3 percentage points for girls aged 12-14 in rural areas. With a similar grant amount (of around 3 U.S dollars per month) we

\footnotetext{
${ }^{36}$ The endogeneity of father's income is addressed in sub-section 4.3

${ }^{37}$ See Attanasio et al. (2012) for more details on the Oportunidades grants.

${ }^{38}$ This paper is discussed and analyzed in the Conditional cash transfers policy research report by Fiszbein and Schady (2009).
} 
simulate this gender CCT program, estimating an impact of almost 1 p.p. for girls in the same group age.

The difference in the results can be explained by the following reasons. First, the baseline is much lower than the one studied in this paper (29 and 50 percent, respectively). Second, the program was addressed to the less literate regions ${ }^{39}$, where only one (Rahim Yar Khan) of our three districts would have been included in the original program ${ }^{40}$. In this case, their results are naturally more sensitive to an income effect. Finally, the program targeted only public schools and the high percentage of private schools in our sample may affect the results in an unclear way. Therefore, it can be said that the model simulates relatively well the results from the Female School Stipend Program in Punjab.

\subsubsection{Grant increasing with years of schooling completed}

The simulation includes monthly grants for children of a family qualified as beneficiary ${ }^{41}$. To be given a grant, children need to be enrolled in school. A child who does not pass a grade is still eligible for the grant ${ }^{42}$. The grant increases with the years of schooling completed in a very similar way to the well known CCT program in Mexico (Oportunidades). In addition, using other CCT schemes (Fiszbein and Schady (2009)), we built a lower and an upper bound for the impact on school participation.

Table A-4 in appendix shows the grant scheme used in both scenarios, one in which the secondary school grant is around 3.5 percent of the average income of the household (Lower bound scenario - CCT(L)) and another in which the same grant reaches 30 percent of the average income of the household (Upper bound scenario - CCT(U)).

Figure 5 shows that the CCT program would have a positive and increasing impact on school enrollment, especially after 12 years of age using the upper bound scenario $(\mathrm{CCT}(\mathrm{U}))$.

The average impact for girls between 12 and 15 is around 3.5 percentage points, while for younger girls is around 1 percentage point. Using the lower bound scenario (CCT(L)) the results become much more modest, reaching for older girls an impact of less than 1

\footnotetext{
${ }^{39}$ Fifteen of Punjabs 34 districts were selected as program districts on the basis of average literacy rate of population 10 years old and older. The average literacy was estimated from Population Census 1998 data. The cut-off literacy rate was 40 percent: 15 selected districts below the cut-off were stipend-eligible and the remaining 19 above the cut-off were not.

${ }^{40}$ Rahim Yar Khan was not among the worst ones, having a literacy rate of around 33 percent (in an interval from 20 to 40 percent). Attock and Faisalabad presented higher literacy rates (49 and 52 percent, respectively).

${ }^{41}$ This excludes the ones above the 95 th percentile of the distribution.

${ }^{42}$ In Oportunidades if the child fails the same grade twice, she/he loses eligibility. This is not taken into account in this simulation.
} 
Figure 5: Conditional Cash Transfer - Grant increasing with years of schooling - impact on girls' school enrollment rates

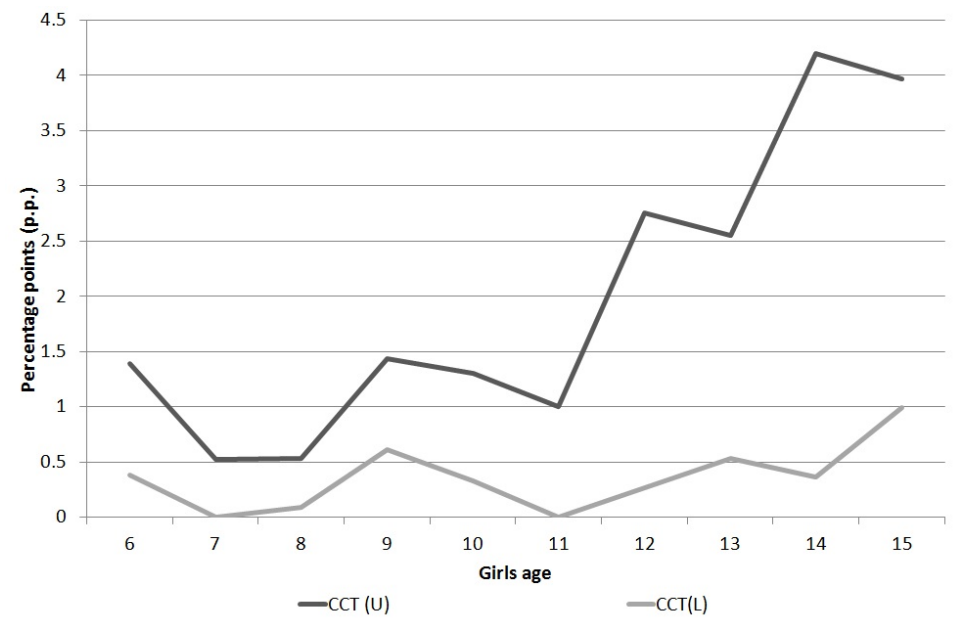

Notes: This figure shows the impact, in percentage points, on girls' school enrollment rate of the conditional cash transfer scheme presented in Table A-4. $\mathrm{CCT}(\mathrm{U})$ represents the upper bound case, in which the secondary school grant represents around 30 percent of average household income. CCT(L) represents the lower bound case, in which the secondary school grant represents around 3.5 percent of average household income.

percentage point and having a negligible effect on younger girls.

In general, the impact of this measure on mothers' labor market participation is modest (see Table A-8 in appendix).

Interestingly, in terms of welfare, the impact of the CCT program is positive but decreasing in both scenarios. Using the upper bound scenario, the utility gain for girls aged 11 to 13 is equivalent to an increase in income of 15.5 percent, while for girls aged 14 to 15 it is equivalent to a 9.5 percent increase. The effects in the lower bound scenario are smaller and equivalent to an income positive variation of 2.3 and 1.3 percent, respectively.

\subsubsection{Same Grant for all grades}

In this simulation the grant does not increase with the years of schooling completed. Table A-5 in appendix shows the grant scheme and Figure 6 shows the impact of this simulation. As before, we simulate two different scenarios, one in which the monthly grant is around 3 percent of the average income of the household, and another in which the same grant reaches 30 percent of the average income of the household.

Interestingly, even with the same grant for all years of schooling completed, the CCT program would have a positive and increasing impact on school enrollment especially after 
Figure 6: Conditional Cash Transfer - Same grant for all grades - impact on girls' school enrollment rates

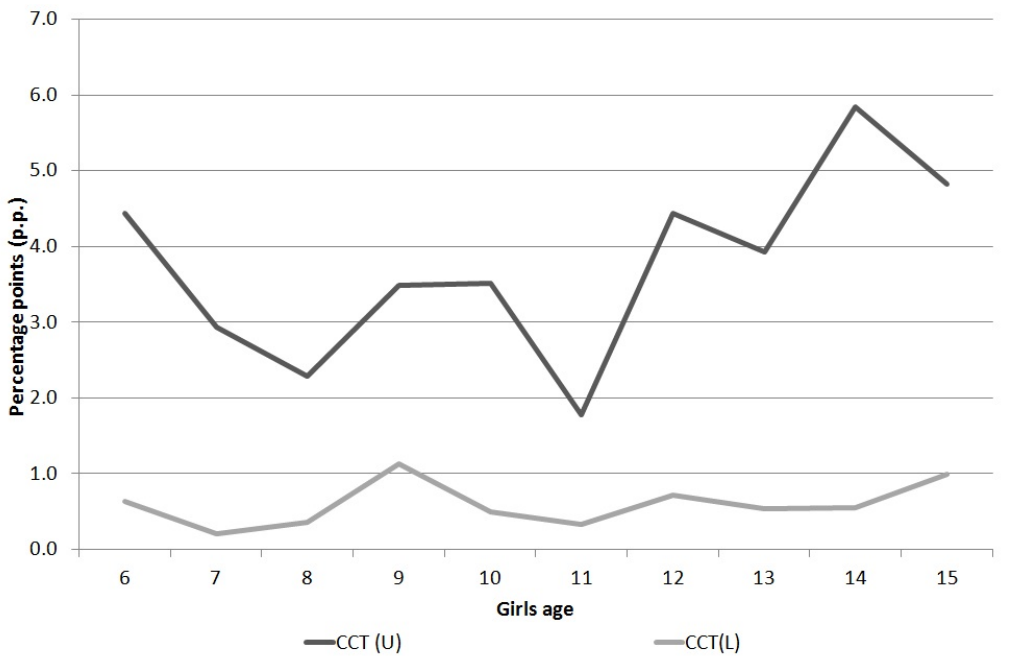

Notes: This figure shows the impact, in percentage points, on girls' school enrollment rate of the conditional cash transfer scheme presented in Table A-5. $\mathrm{CCT}(\mathrm{U})$ represents the upper bound case, in which the grant represents around 30 percent of average household income. CCT(L) represents the lower bound case, in which the grant represents around 3.5 percent of average household income.

12 years of age, using the Upper bound scenario $(\mathrm{CCT}(\mathrm{U}))$. The average impact for girls between 12 and 15 is around 5 percentage points, while for younger girls is around 3 percentage points. In the Lower bound scenario the impact on girls' enrollment rate increases slightly, to be on average around 0.6 percentage points and similar for younger and older girls.

As before, in terms of welfare, the impact of the program is positive but decreasing. The utility gain for girls aged 11 to 13 is equivalent to an increase of income by 21.5 percent using the upper bound scenario, while for the older girls it is equivalent to an increase of 12.2 percent. The effects in the lower bound scenario are smaller and equivalent to an increase in income of less than 3.5 percent.

\subsubsection{Which grant would close the enrollment rate gender gap?}

Finally, we present the results for the simulation in which the CCT grant would close the school enrollment rate gender gap. Table A-6 in appendix shows the observed school enrollment gender gap in the sample and Table A-7 in appendix shows the grant scheme required to close such large differences.

For younger girls the average gender gap reaches on average 10 percentage points, while 
for girls aged 14 and 15, reaches an average of 25 percentage points. In the Primary school the level of the grant needs to be similar or slightly above the average household income. In the Secondary school, for grades 6 and 7 the grant has to be almost twice the household average income, and would need to be three times greater for the students in grade 8 or above. As we can see, it would be very costly to close the gender gap using only a program like the conditional cash transfer. To close the gap the grant for older girls needs to be around 10 times greater than the most generous CCT program that has already taken place, which reaches around 30 percent of the household average income. In terms of welfare, closing the school enrollment gender gap would provide a utility gain equivalent to an increase in income of around 100 percent.

\subsection{Unconditional Cash Transfer}

Table 5 compares the results of the conditional cash transfer (CCT) with an unconditional cash transfer (UCT) program. The impact of the UCT scheme is much smaller in both cases, lower and upper bound scenarios. Nevertheless, the higher the grant the greater the difference between the two schemes. On average, for older girls the impact of the UCT upper bound scenario is only 15 percent as large as the CCT scheme and 28 percent in the lower bound scenario. Furthermore, the CCT(L), which corresponds to a grant of around 3.5 percent of household income, yields results slightly better than the ones presented by $\mathrm{UCT}(\mathrm{U})$ with a grant 8 times larger.

These results are in line with recent papers (Baird et al. (2011) and Attanasio et al. (2015)) confirming large effects of the conditionality ${ }^{43}$. Therefore, this exercise confirms and quantifies from a policy perspective the widespread use of CCT schemes. In particular, when education is to be targeted, the need and importance of a conditional incentives scheme seems clear.

In terms of welfare, with this scheme (same grant for the UCT and CCT) we obtain as expected a higher utility gain for the UCT as the number of people receiving the grant is also higher. Nevertheless, a cost comparable version of the UCT and CCT would provide similar impacts in terms of welfare, except for the older girls, in which the UCT would provide a higher utility gain. In this case, the effect of the CCT scheme on older girls would provide a utility gain equivalent to an increase in income of 12.2 percent, which is around 90 percent as large as the UCT version.

\footnotetext{
${ }^{43}$ Baird et al. (2011) assess the role of conditionality in a cash transfer program using an experiment with adolescent girls in Malawi. In their paper the impact of the UCT scheme on drop-out rate was only 43 percent as large as the impact of the CCT.
} 
Table 5: Unconditional vs. Conditional cash transfer - Same Grant for all grades

\begin{tabular}{|c|c|c|c|c|c|c|c|c|c|c|}
\hline & \multicolumn{10}{|c|}{ Girls' age } \\
\hline Policy measures & 6 & 7 & 8 & 9 & 10 & 11 & 12 & 13 & 14 & 15 \\
\hline \multicolumn{11}{|c|}{ Upper Bound Scenario - (around 30 percent of household average income) } \\
\hline $\mathrm{CCT}(\mathrm{U})$ & 4.4 & 2.9 & 2.3 & 3.5 & 3.5 & 1.8 & 4.4 & 3.9 & 5.8 & 4.8 \\
\hline UCT (U) & 0.1 & 0.0 & 0.1 & 0.0 & 0.1 & 0.0 & 0.2 & 0.2 & 0.5 & 0.7 \\
\hline \multicolumn{11}{|c|}{ Lower Bound Scenario - (around 3.5 percent of household average income) } \\
\hline CCT (L) & 0.6 & 0.2 & 0.4 & 1.1 & 0.5 & 0.3 & 0.7 & 0.5 & 0.5 & 1.0 \\
\hline UCT (L) & 0.0 & 0.0 & 0.0 & 0.0 & 0.0 & 0.0 & 0.1 & 0.1 & 0.3 & 0.3 \\
\hline
\end{tabular}

Notes: This table compares the impact, in percentage points, of the unconditional with the conditional cash transfer policy on girls' school enrollment rate. $\mathrm{CCT}(\mathrm{U})$ and $\mathrm{UCT}(\mathrm{U})$ - It reports the upper bound case for the Conditional and Unconditional cash Transfer, respectively, in which the secondary school grant represents around 30 percent of average household income. CCT $(\mathrm{L})$ and $\mathrm{UCT}(\mathrm{L})$ - It reports the lower bound case for the Conditional and Unconditional cash Transfer, respectively, in which the secondary school grant represents around 3.5 percent of average household income. 


\subsection{Availability of Secondary Schools}

Access to the school has been an important factor inhibiting girls' enrollment, especially in rural areas. Changes in government educational policy in recent years, as well as the rapid growth of low-fee private schools in rural areas, may be changing the educational opportunity structure for poor rural girls. Duflo (2001) shows the importance of this type of intervention in developing countries, in particular reporting the effectiveness in increasing both education and wages.

Nevertheless, not having a secondary school in the village of residence implies transportation and time costs. Both costs decrease the utility of attending school. For example, if the government establishes a secondary school in one of those villages, a positive effect on school enrollment could be expected. In the next experiment we demonstrate the effects of a potential but ambitious school building program, in which all villages would have at least one secondary school for girls (Figure 7). The impact increases with children's age and reaches a maximum of around 2.5 percentage points for the oldest girls.

The results are significant and bigger than the cost comparable CCT scenario, in particular looking at older girls (14 and 15 years old) the impact on the girls' school enrollment rate is almost three times greater. The cost per student of this type of measure was calculated to be of around 465 rupees per month $(\approx 5.4 \text { U.S. dollars })^{44}$. This measure can be seen not only as an alternative but also as a complement from an education policy perspective that wishes to target high drop-out rates among girls in a more effective and direct way.

Notice that, on one hand the results may be underestimated, since we are not taking into account the extra positive effect of building schools in villages where a school is already available and crowded. Furthermore, if we had used the same estimated total cost of the school building program (per year) instead of the cost per student, the effect on the CCT scheme would have been even smaller. Finally, this effect relies on the assumption that the government builds a school in all villages initially without one.

Furthermore, as the CCT scheme is an anti-poverty program and not only an educational program, it is also important to look at the impacts on welfare. As expected, in terms of welfare the difference between the two schemes is much smaller. The utility gain of the school building program is equivalent to an increase in income of around 3 percent. The CCT cost comparable scheme effects are 83 percent as large as the school building program (compared to only 34 percent in terms of enrollment).

\footnotetext{
${ }^{44}$ The cost per student per month is calculated in the following way: from other school building programs (from World Bank and other institutions) we use an estimate of around $\$ 7000$ per classroom. Then, we assume i) 20 years without major reforms, ii) on average 30 children per classroom, and iii) a student will stay on average 5 years.
} 
Figure 7: School Building Program vs. Conditional Cash Transfer (impact on girls' school enrollment rate)

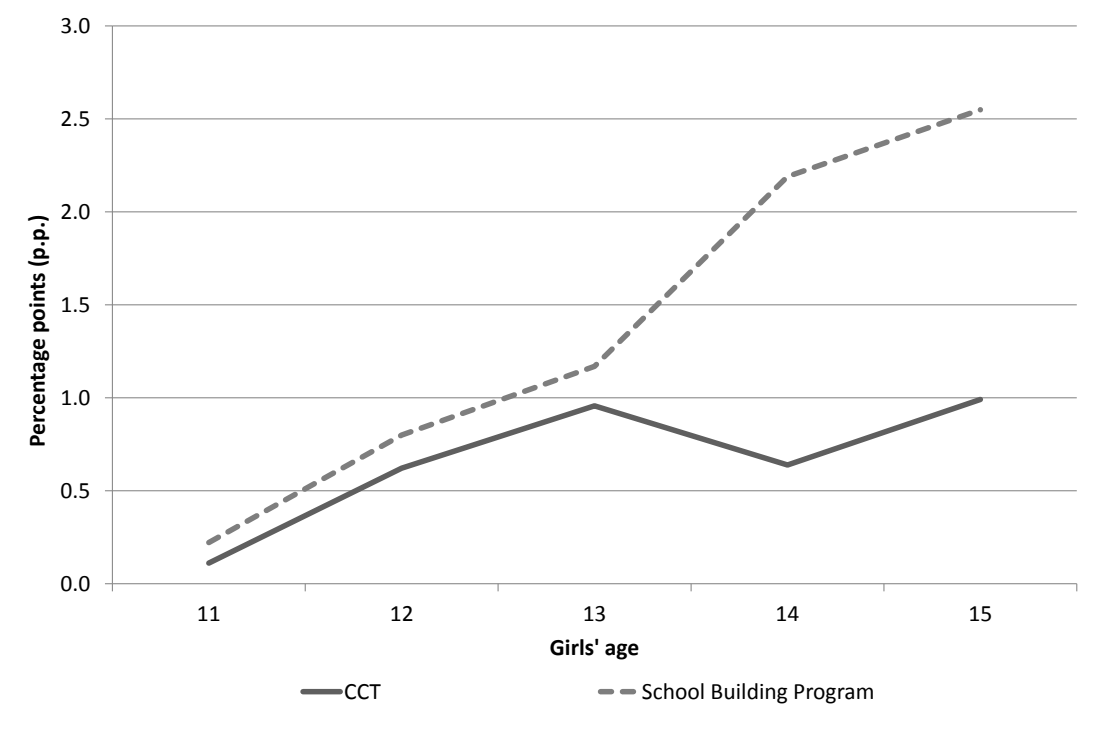

Notes: This figure compares the impact, in percentage points, of the school building program with the conditional cash transfer program on girls' school enrollment rate. The two policies are cost comparable - the cost per student in a secondary school of around 465 rupees per month $(\approx 5.4$ U.S. dollars)). The cost per student per month is calculated in the following way: using an estimate of around $\$ 7000$ per classroom (source: other school building programs) and assuming i) 20 years without major reforms, ii) on average 30 children per classroom, and iii) a student will stay on average 5 years.

1 US dollar $\approx 85.6$ PAK rupees.

Interestingly, Table A-8 in appendix shows that there is a negative impact on mothers' labor market participation for older girls, reaching a maximum impact of -0.65 percentage points when the girl is 14 years old. This seems to be a result of the substitutability between mothers and girls in working at home.

\subsection{Employment subsidy}

Another interesting experiment is to determine the impact of an employment subsidy (or wage subsidy) ${ }^{45}$ on girls' school enrollment and mother's labor market participation (Figure 8). We present the results of an increase in wages by 10 and 20 percent.

In both cases the effect on girls' school enrollment is modest, more so for the youngest

\footnotetext{
${ }^{45}$ This policy would be in the same spirit of the Working Tax Credit in the United Kingdom.
} 
Figure 8: Wage increase

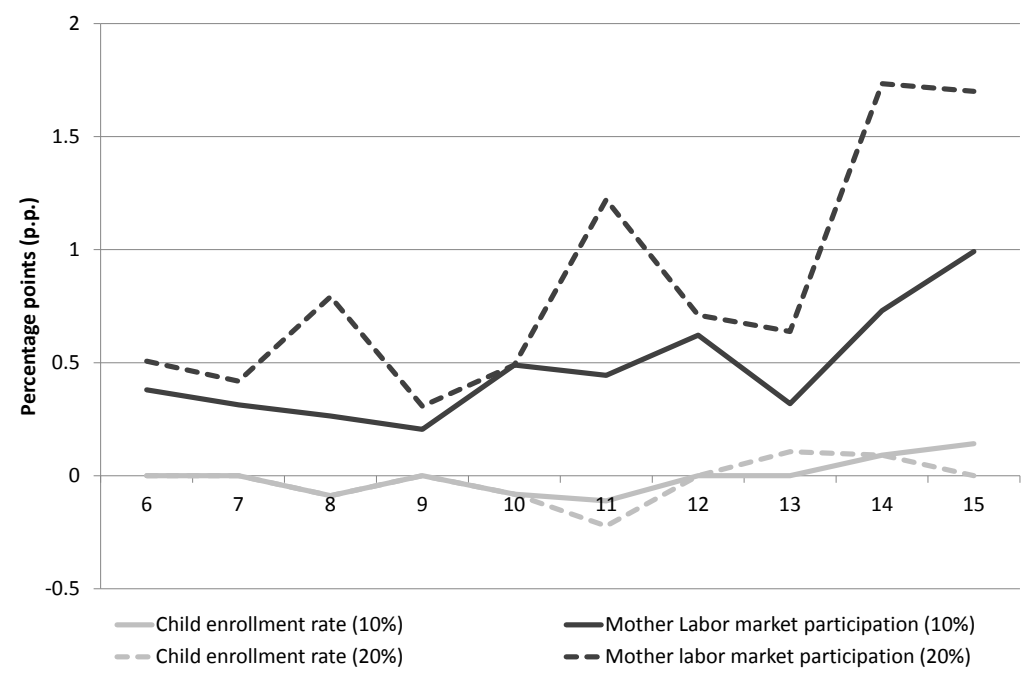

Note: This figure shows the impact, in percentage points, on girls' school enrollment rate and mother's labor market participation rate of an increase in wages by 10 and 20 percent.

girls. To a large extent this is explained by the high substitutability between home and market production (see Table 2) observed in the model. Interestingly, for a mother with an older girl, we may end up with a small but negative impact. In this case, the substitution effect becomes more important than the income effect. As for the mother's labor market participation, the impact is positive and increasing in both scenarios. The impact of an increase in wages by 20 percent reaches a maximum of 1.8 percentage points, when the child is 15 years old (around 1 percentage point for the 10 percent increase).

\subsection{The effect of a more educated generation}

As mentioned above, the most traditional attitudes toward girls' schooling tend to be held by the older and less educated population. Therefore, there is a positive generation effect that is interesting to quantify and that should be taken into account. In this case we simulate and quantify what happens to girls' school attendance if mothers' education distribution is different, i.e., in the way the model predicts. In one generation (10 to 15 years), the oldest population (50-65 years old) would be out and replaced by the generation analyzed in the model. The figures are clear: among the oldest population, the percentage of educated mothers is around 5 percent, compared to the 60 to 65 percent in the youngest 
generation. In practical terms, the overall percentage of educated mothers rises from 25 to 30 percent. This simple exercise is an underestimation of a pure generation effect, as it does not take into account other preference changes that, of course, are also taking place. The impact on older girls is around 1.5 percentage points, which is relatively modest. Despite the other factors that are not taken into account in this exercise, this is just a confirmation that any cultural change takes time to have a clear and visible effect.

\section{Concluding Remarks}

In this paper we focus on the children schooling and labor supply decisions of women using and estimating a dynamic behavioral model in rural Pakistan. Our research is relevant not only for Pakistan, but also for other low-income countries aiming to reduce high drop-out rates among older girls. The mechanisms and the consequences of different policies may provide good insight to other lower-income countries from a policy perspective.

This paper seeks to explain the high drop-out rates among girls, in particular, the role of home production for older girls, and the impact of monetary incentives and supply side education policies on girls' school enrollment. Earlier studies have provided evidence that these incentives are important to increase school attendance but never combine mother labor supply with children schooling decision, and the key role played by home production. Results in this paper show that mothers' working status affects the girls' utility of staying at home. A girl whose mother works in the labor market is estimated to be more valuable at home. Also, the family composition, especially the number of young children, has an important role for the value of both mother and girls being at home. The model highlights the relevance of economic factors, through budget constraint and home production, in the decision of children attending school. The importance of cultural factors is also incorporated in the household's preferences. Estimation of the structural model allows us to explore the effects of counterfactual policy experiments. Simulations suggest that monetary incentives are a good mechanism to keep and increase girls' school enrollment, such as the conditional cash transfer case. Nevertheless, to obtain sizable effects it is too costly when compared with alternatives, in particular with a school building program. Therefore, the paper shows that in rural areas CCT programs are clearly not the only way to target educational attainment, in particular when some basic school environments and resources are not attained. In terms of welfare, the CCT scheme and the alternative policies provide

similar results. Finally, the paper provides evidence that independently of the nature of the incentives, it will take time to realize visible and sizeable effects on girls' educational participation. 


\section{A Appendix Tables}

Table A-1: Girls' age distribution

\begin{tabular}{rrr}
\hline Age & Observations & Percentage \\
\hline 6 & 158 & 8.0 \\
7 & 191 & 9.7 \\
8 & 227 & 11.5 \\
9 & 195 & 9.9 \\
10 & 245 & 12.4 \\
11 & 180 & 9.1 \\
12 & 225 & 11.4 \\
13 & 188 & 9.6 \\
14 & 219 & 11.1 \\
15 & 141 & 7.2 \\
\hline & 1969 & 100.0 \\
\hline
\end{tabular}

Note: This table shows the girls' age distribution between 6 and 15 years of age, which represents around 75 percent of all girls less than 16 years old.

Table A-2: Variance-Covariance Matrix

\begin{tabular}{lrr}
\hline Parameter & Estimate & \multicolumn{2}{c}{ Standard Error } \\
\hline $\operatorname{var}\left(\epsilon_{t}^{(0,1)}\right)-\operatorname{var}\left(\epsilon_{t}^{(0,1)}\right)$ & - & - \\
$\operatorname{var}\left(\epsilon_{t}^{(1,1)}\right)-\operatorname{var}\left(\epsilon_{t}^{(0,1)}\right)$ & 1 & - \\
$\operatorname{var}\left(\epsilon_{t}^{(0,0)}\right)-\operatorname{var}\left(\epsilon_{t}^{(0,1)}\right)$ & 4.71 & 0.003 \\
$\operatorname{var}\left(\epsilon_{t}^{(1,0)}\right)-\operatorname{var}\left(\epsilon_{t}^{(0,1)}\right)$ & 0.04 & 0.005 \\
\hline
\end{tabular}

Note: This table shows the variance estimates and the asymptotic standard errors. The variance-covariance matrix was estimated using the GHK method. The results are in utility differences with the alternative school/not working. 
Table A-3: Probability of passing grade

\begin{tabular}{|c|c|c|c|c|c|c|c|c|c|c|}
\hline \multirow[b]{2}{*}{ Girls' Education } & \multicolumn{10}{|c|}{ Girls' Age } \\
\hline & 6 & 7 & 8 & 9 & 10 & 11 & 12 & 13 & 14 & 15 \\
\hline 0 & 0.36 & 0.46 & 0.67 & 0.85 & 0.86 & 0.83 & 0.40 & 0.67 & 0.67 & 0.00 \\
\hline 1 & 0.42 & 0.51 & 0.72 & 0.64 & 0.80 & 0.71 & 0.78 & 0.75 & 0.25 & 0.00 \\
\hline 2 & 0.00 & 0.70 & 0.62 & 0.77 & 0.79 & 0.84 & 0.69 & 0.52 & 0.76 & 0.50 \\
\hline 3 & 0.00 & 0.00 & 0.63 & 0.48 & 0.65 & 0.80 & 0.66 & 0.59 & 0.86 & 0.65 \\
\hline 4 & 0.00 & 0.00 & 0.00 & 0.50 & 0.77 & 0.73 & 0.76 & 0.78 & 0.80 & 0.71 \\
\hline 5 & 0.00 & 0.00 & 0.00 & 0.00 & 0.20 & 0.80 & 0.41 & 0.41 & 0.38 & 0.20 \\
\hline 6 & 0.00 & 0.00 & 0.00 & 0.00 & 0.00 & 0.71 & 0.74 & 0.60 & 0.78 & 0.61 \\
\hline 7 & 0.00 & 0.00 & 0.00 & 0.00 & 0.00 & 0.00 & 0.60 & 0.62 & 0.73 & 0.58 \\
\hline 8 & 0.00 & 0.00 & 0.00 & 0.00 & 0.00 & 0.00 & 0.00 & 0.50 & 0.69 & 0.73 \\
\hline 9 & 0.00 & 0.00 & 0.00 & 0.00 & 0.00 & 0.00 & 0.00 & 0.00 & 0.40 & 0.67 \\
\hline 10 & 0.00 & 0.00 & 0.00 & 0.00 & 0.00 & 0.00 & 0.00 & 0.00 & 0.00 & 0.50 \\
\hline
\end{tabular}

Mother's Education - at least some education

\begin{tabular}{lrrrrrrrrrr}
\hline & \multicolumn{10}{c}{ Girls' Age } \\
\hline Girls' Education & 6 & 7 & 8 & 9 & 10 & 11 & 12 & 13 & 14 & 15 \\
\hline 0 & 0.52 & 0.74 & 0.86 & 0.78 & 0.67 & 0.67 & 0.40 & 0.67 & 0.67 & 0.00 \\
1 & 0.38 & 0.63 & 0.67 & 0.76 & 0.86 & 0.68 & 0.75 & 0.75 & 0.50 & 0.00 \\
2 & 0.00 & 0.50 & 0.82 & 0.77 & 0.86 & 0.89 & 0.87 & 0.76 & 0.50 & 0.00 \\
3 & 0.00 & 0.00 & 0.72 & 0.59 & 0.67 & 0.83 & 0.74 & 0.79 & 0.95 & 0.00 \\
4 & 0.00 & 0.00 & 0.00 & 0.82 & 0.74 & 0.78 & 0.83 & 0.68 & 0.82 & 0.88 \\
5 & 0.00 & 0.00 & 0.00 & 0.00 & 0.50 & 0.63 & 0.42 & 0.63 & 0.36 & 0.14 \\
6 & 0.00 & 0.00 & 0.00 & 0.00 & 0.00 & 0.57 & 0.79 & 0.78 & 0.95 & 0.43 \\
7 & 0.00 & 0.00 & 0.00 & 0.00 & 0.00 & 0.00 & 0.80 & 0.60 & 0.78 & 0.73 \\
8 & 0.00 & 0.00 & 0.00 & 0.00 & 0.00 & 0.00 & 0.00 & 0.56 & 0.92 & 0.85 \\
9 & 0.00 & 0.00 & 0.00 & 0.00 & 0.00 & 0.00 & 0.00 & 0.00 & 0.20 & 0.64 \\
10 & 0.00 & 0.00 & 0.00 & 0.00 & 0.00 & 0.00 & 0.00 & 0.00 & 0.00 & 0.67 \\
\hline
\end{tabular}

Notes: We estimate the probability of progressing for each grade as the ratio of individuals who passed to the next grade compared to the year before at a particular age, given their education and their mother's education. Mother's education is a binary variable, which can represent a mother with no education or a mother with at least some education. 
Table A-4: Grant increasing with the years of schooling (in U.S dollars per month)

\begin{tabular}{lrr}
\hline Grade & $\mathrm{CCT}(\mathrm{U})$ & $\mathrm{CCT}(\mathrm{L})$ \\
\hline & & \\
Primary education & & \\
& & \\
grade 1 to 4 & 11.7 & 1.8 \\
grade 5 & & \\
& & \\
Secondary education & & \\
& & \\
grade 6 to 7 & 23.4 & 3.5 \\
grade 8 or more & 29.2 & 4.4 \\
\hline
\end{tabular}

Notes: This table shows the grant scheme of the conditional cash transfer simulated in the model similar to the Oportunidades scheme. CCT (U) represents the upper bound case, in which the secondary school grant represents around 30 percent of average income. CCT (L) represents the lower bound case, in which the secondary school grant represents around 3.5 percent of average income.

Table A-5: Same Grant for all grades (in U.S dollars per month)

\begin{tabular}{lrr}
\hline Grade & CCT $(\mathrm{U})$ & CCT $(\mathrm{L})$ \\
\hline All grades & 23.4 & 3.5 \\
& & \\
\hline
\end{tabular}

Notes: This table shows the grant scheme of the conditional cash transfer simulated in the model, in which the grant is the same for all grades. CCT (U) represents the upper bound case, in which the grant represents around 30 percent of average income. CCT (L) represents the lower bound case, in which the grant represents around 3.5 percent of average income. 
Table A-6: School Enrollment Rate by age - Gender gap

\begin{tabular}{rrrrrrrrrrr}
\hline & \multicolumn{10}{c}{ Age } \\
\hline & 6 & 7 & 8 & 9 & 10 & 11 & 12 & 13 & 14 & 15 \\
\hline \multirow{2}{*}{ Gender Gap } & 10.9 & 9.56 & 5.5 & 7.4 & 10.8 & 6.1 & 10.0 & 17.5 & 27.0 & 22.6 \\
& & & & & & & & & & \\
\hline
\end{tabular}

Notes: This table shows the school enrollment gender gap by age.

Table A-7: Grant Scheme - Closing Gender Gap (in U.S dollars per month)

\begin{tabular}{lrr}
\hline Grade & CCT & $\begin{array}{r}\text { \% of household } \\
\text { average income }\end{array}$ \\
\hline Primary & & \\
& & 100.0 \\
grade 1 to 4 & 82 & 114.3 \\
grade 5 & 94 & \\
Secondary & & \\
& & 185.7 \\
grade 6 to 7 & 152 & 300.0 \\
grade 8 or more & 245 &
\end{tabular}

Notes: This table shows the grant scheme of the conditional cash transfer simulated in the model which closes the gender gap in terms of school enrollment rates. It also shows the percentage of each grant in terms of the household average income.

Table A-8: Impact on mother's labor market participation rate

\begin{tabular}{lcc}
\hline & \multicolumn{2}{c}{ Girls' age } \\
\hline Policy measures & $6-10$ & $11-15$ \\
\hline CCT $(\mathrm{U})$ & 0.04 & -0.02 \\
School Building Program & 0.06 & -0.07 \\
\hline
\end{tabular}

Notes: This table shows the impact, in percentage points, on mother's labor market participation rate of the Conditional cash transfer scheme (Upper bound scenario), the school building program. The table displays the average impact for younger girls (6 to 10 years old) and for older girls (11 to 15 years old). 


\section{B Appendix Figures}

Figure A-1: Household choice distribution

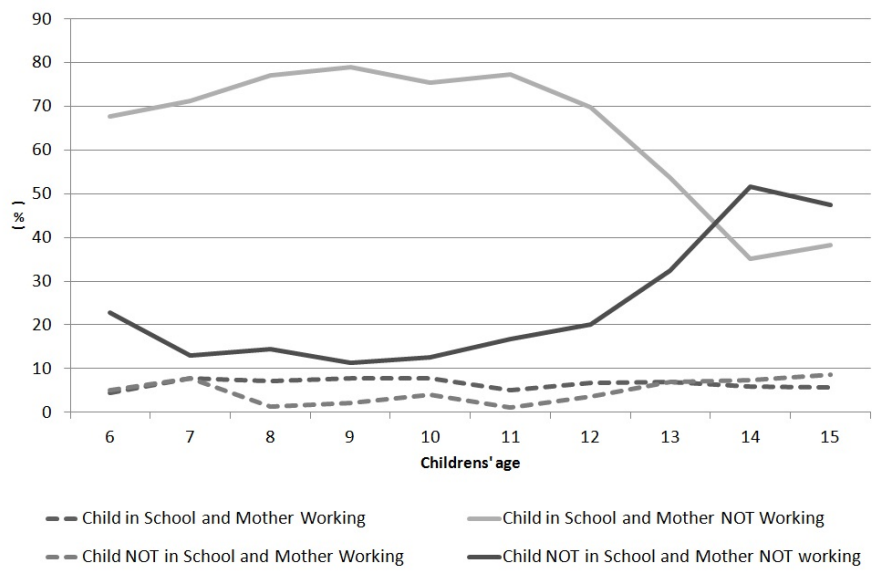

Note: This figure shows the four mutually exclusive household choices distribution.

Figure A-2: Preferences by age

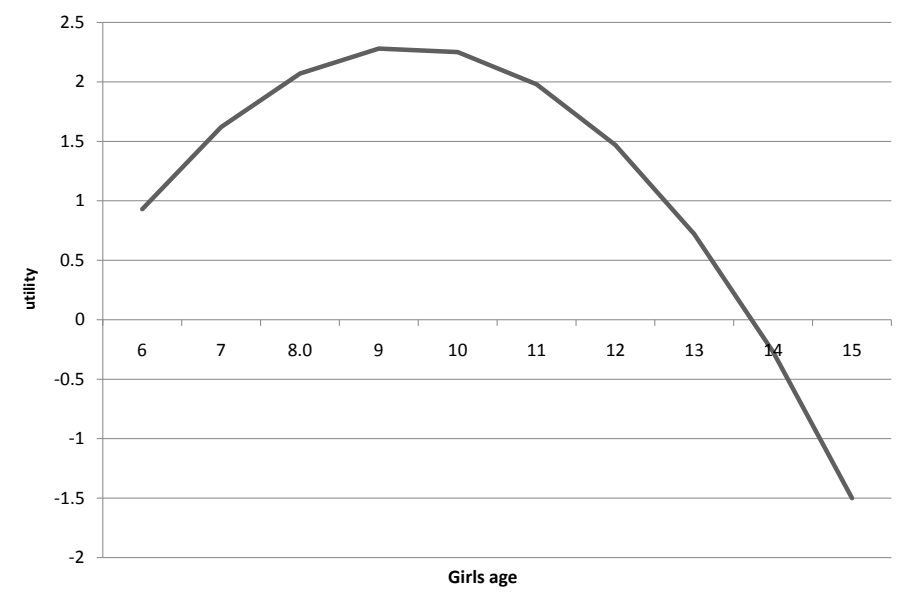

Note: This figure shows the girls' age profile of mother's preferences in taste for child education in utility terms. 
Figure A-3: Model fit - household choice distribution
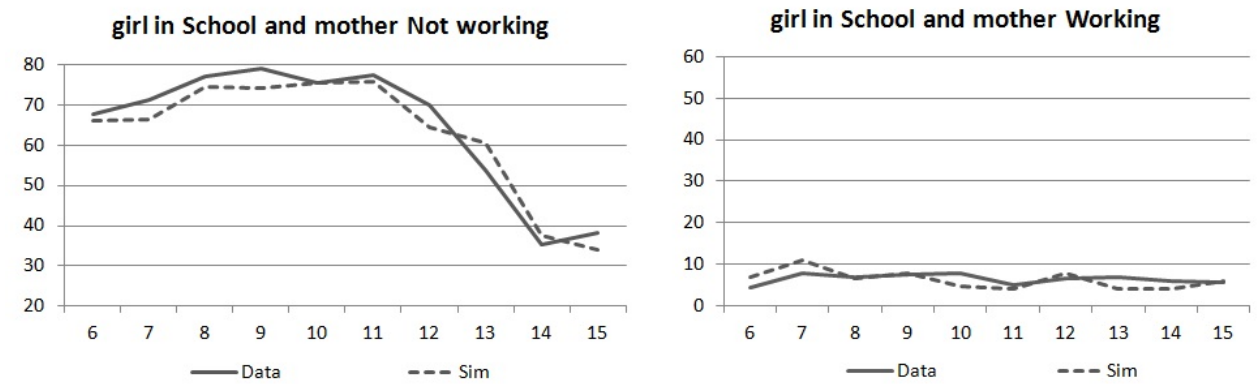

girl Not in school and mother Not working
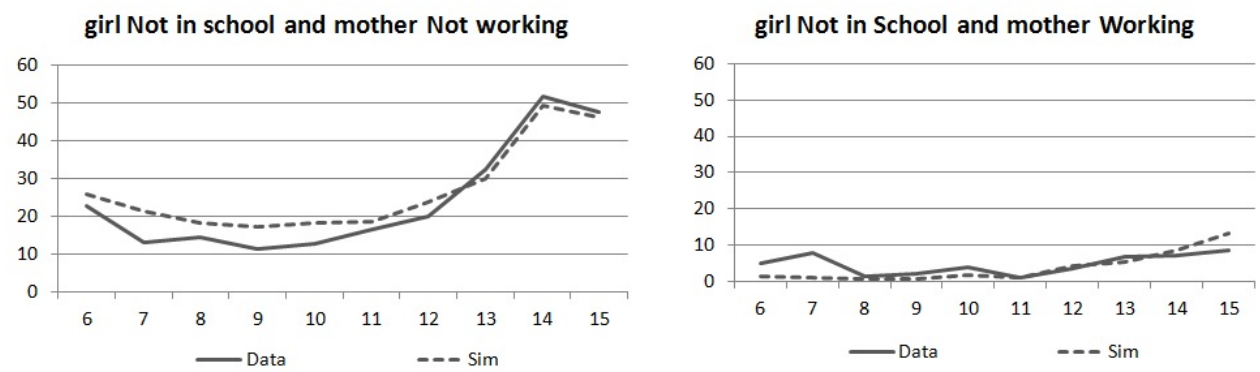

Note: This figure shows the model fit for the four mutually exclusive household choices.

Figure A-4: Model fit - Girls' school enrollment rate by number of young children
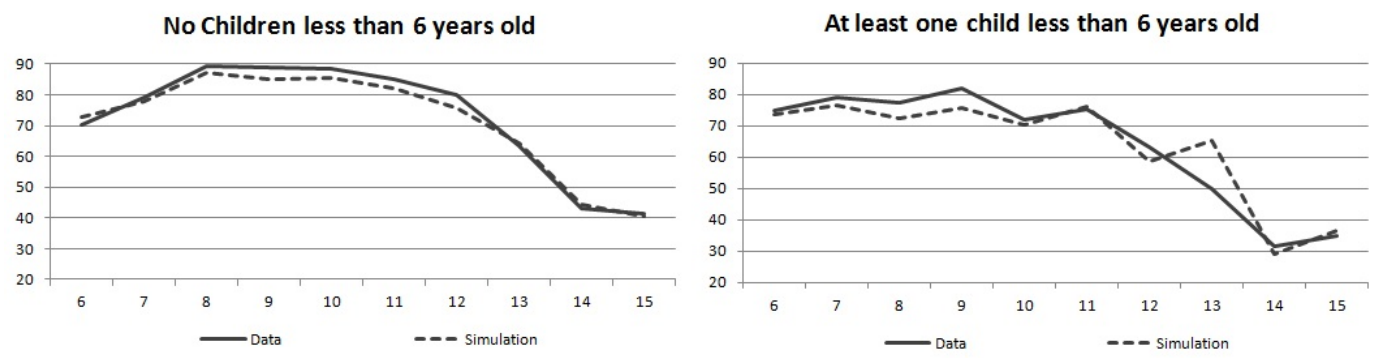

Note: This figure compares the model fit for the girls' school enrollment rate for households with and without children less than 6 years old. 


\section{References}

Aguirregabiria, V. (2010). Another look at the identification of dynamic discrete decision processes: An application to retirement behavior. Journal of Business 8 Economic Statistics, 28(2):201-218.

Aguirregabiria, V. and Mira, P. (2010). Dynamic discrete choice structural models: A survey. Journal of Econometrics, 156(1):38-67.

Ahmed, W., Haider, A., and Iqbal, J. (2012). Estimation of discount factor (beta) and coefficient of relative risk aversion (gamma) in selected countries. Mpra paper, University Library of Munich, Germany.

Attanasio, O. P., Meghir, C., and Santiago, A. (2012). Education choices in mexico: Using a structural model and a randomized experiment to evaluate progresa. The Review of Economic Studies, 79(1):37-66.

Attanasio, O. P., Oppedisano, V., and Vera-Hernandez, M. (2015). Should cash transfers be conditional? conditionality, preventive care, and health outcomes. American Economic Journal: Applied Economics, 7(2):35-52.

Baird, S., McIntosh, C., and Özler, B. (2011). Cash or condition? evidence from a cash transfer experiment. The Quarterly Journal of Economics, 126(4):1709-1753.

Behrman, J. R. (1997). Mother's Schooling and Child Education: A Survey. University of Pennsylvania - Institute for Economic Research.

Behrman, J. R., Foster, A. D., Rosenzweig, M. R., and Vashishtha, P. (1999). Women's Schooling, Home Teaching, and Economic Growth. Journal of Political Economy, University of Chicago Press, 107(4):682-714.

Bernal, R. (2008). The effect of maternal employment and child care on children's cognitive development. International Economic Review, 49(4):1173-1209.

Cardenas, J. C. and Carpenter, J. (2008). Behavioural development economics: Lessons from field labs in the developing world. Journal of Development Studies, 44(3):311-338.

Carneiro, P., Das, J., and Reis, H. (2015). Parental valuation of school attributes in developing countries: Evidence from pakistan. unpublished manuscript, University College London.

Chaudhury, N. and Parajuli, D. (2010). Conditional cash transfers and female schooling: the impact of the female school stipend programme on public school enrolments in punjab, pakistan. Applied Economics, 42(28):3565-3583.

Del Boca, D. and Flinn, C. J. (2014). Household behavior and the marriage market. Journal of Economic Theory, 150(C):515-550.

Duflo, E. (2001). Schooling and labor market consequences of school construction in indonesia: Evidence from an unusual policy experiment. American Economic Review, 91(4):795-813. 
Eckstein, Z. and Lifshitz, O. (2011). Dynamic female labor supply. Econometrica, $79(6): 1675-1726$.

Fiszbein, A. and Schady, N. (2009). Conditional Cash Transfers: Reducing Present and Future Poverty. World Bank policy research report.

Geweke, J., Keane, M. P., and Runkle, D. (1994). Alternative computational approaches to inference in the multinomial probit model. The Review of Economics and Statistics, 76(4):609-32.

Greenwood, J., Rogerson, R., and Wright, R. (1993). Putting home economics into macroeconomics. Quarterly Review, (Sum):2-11.

Hasan, A. (2010). Gender-targeted conditional cash transfers : enrollment, spillover effects and instructional quality. Policy Research Working Paper Series 5257, The World Bank.

Heckman, J. and Singer, B. (1984). A method for minimizing the impact of distributional assumptions in econometric models for duration data. Econometrica, 52(2):271-320.

Keane, M. P. (1994). A computationally practical simulation estimator for panel data. Econometrica, 62(1):95-116.

Keane, M. P., Todd, P. E., and Wolpin, K. I. (2011). The Structural Estimation of Behavioral Models: Discrete Choice Dynamic Programming Methods and Applications, volume 4 of Handbook of Labor Economics, chapter 4, pages 331-461. Elsevier.

Keane, M. P. and Wolpin, K. I. (1997). The career decisions of young men. Journal of Political Economy, 105(3):473-522.

Magnac, T. and Thesmar, D. (2002). Identifying dynamic discrete decision processes. Econometrica, 70(2):801-816.

MDG (2010). Pakistan millennium development goals - report 2010. Technical report, Centre for Povery Reduction and Social Policy Development.

Rust, J. (1994). Structural estimation of markov decision processes, volume 4 of Handbook of Econometrics, chapter 51, pages 3081-3143. Elsevier.

Todd, P. and Wolpin, K. (2006). Assessing the impact of a school subsidy program in mexico: Using a social experiment to validate a dynamic behavioral model of child schooling and fertility. American Economic Review, 96(5):1384-1417.

Todd, P. E. and Wolpin, K. I. (2010). Structural estimation and policy evaluation in developing countries. Annual Review of Economics, 2(1):21-50.

Train, K. (2009). Discrete Choice Methods with Simulation. Cambridge University Press.

World Bank (2014). World development indicators 2014. Technical report. 